NBER WORKING PAPER SERIES

\title{
PUBLIC PROCUREMENT IN LAW AND PRACTICE
}

\author{
Erica Bosio \\ Simeon Djankov \\ Edward L. Glaeser \\ Andrei Shleifer \\ Working Paper 27188 \\ http://www.nber.org/papers/w27188 \\ NATIONAL BUREAU OF ECONOMIC RESEARCH \\ 1050 Massachusetts Avenue \\ Cambridge, MA 02138 \\ May 2020
}

The authors are from the World Bank, the Peterson Institute for International Economics, Harvard University, and Harvard University, respectively. We want to thank Marwa Abdou, Souad Adnane, Yuriy Valentinovich Avramov, Ogma Bale, Elodie Bataille, Liliya F Bulgakova, Édgar Chávez, Albert Nogues i Comas, Kimberly Suarez Contreras, Nadine DiMonte, Viktoriya Ereshchenko, Maria Antonia Quesada Gámez, Emilia Galiano, Marko Grujicic, Youmna Al Hourani, Maksym Iavorskyi, Charlotte Nan Jiang, Victoria Khaitina, Anouk Leger, Joseph Lemoine, Tiziana Londero, Raman Maroz, Nikiforos Meletiadis, Margherita Mellone, Nuno Filipe Mendes Dos Santos, Inés Zabalbeitia Múgica, Sarah Kouhlani Nolla, Nadia Novik, Marion Pinto, Greta Polo, Oleksandra Popova, Parvina Rakhimova, Nathalie Reyes, Silvia Carolina Lopez Rocha, Lucia Arnal Rodriguez, Enrique Orellana Tamez, Erick Tjong, Judith Trasancos, Ferihane Ben Yedder, Farrukh Umarov, Yulia Borisovna Valerio, Rongpeng (Tiffany) Yang, Marilyne Youbi, Philip Zager, Dou Zhang and Muqiao (Chloe) Zhang for excellent research assistance, as well as seminar participants at the Blavatnik School of Government at Oxford University, the London School of Economics and the Peterson Institute for International Economics for their comments. We also benefited from significant help from Valeria Perotti, Utkarsh Saxena, and Yang You, and from comments by Oriana Bandiera, Emanuele Colonnelli, Decio Coviello, Francesco Decarolis, Josh Schwartzstein, Giancarlo Spagnolo, and Dev Patel. The views expressed herein are those of the authors and do not necessarily reflect the views of the National Bureau of Economic Research.

At least one co-author has disclosed a financial relationship of potential relevance for this research. Further information is available online at http://www.nber.org/papers/w27188.ack

NBER working papers are circulated for discussion and comment purposes. They have not been peerreviewed or been subject to the review by the NBER Board of Directors that accompanies official NBER publications.

(C) 2020 by Erica Bosio, Simeon Djankov, Edward L. Glaeser, and Andrei Shleifer. All rights reserved. Short sections of text, not to exceed two paragraphs, may be quoted without explicit permission provided that full credit, including (C) notice, is given to the source. 
Public Procurement in Law and Practice

Erica Bosio, Simeon Djankov, Edward L. Glaeser, and Andrei Shleifer

NBER Working Paper No. 27188

May 2020

JEL No. D73,H11,H57,K42

\begin{abstract}
We examine a new data set of laws and practices governing public procurement, as well as procurement outcomes, in 187 countries. We measure regulation as restrictions on discretion of the procuring agents. We find that laws and practices are highly correlated with each other across countries, better practices are correlated with better outcomes, but laws themselves are not correlated with outcomes. To shed light on this puzzle, we present a model of procurement in which both regulation and public sector capacity determine the efficiency of procurement. In the model, regulation is effective in countries with low public sector capacity, and detrimental in countries with high public sector capacity because it inhibits the socially optimal exercise of discretion. We find evidence broadly consistent with this prediction: regulation of procurement improves outcomes, but only in countries with low public sector capacity.
\end{abstract}

Erica Bosio

World Bank

2121 Pennsylvannia Avenue, NW.

MSN F 3K-234

Washington, DC 20433

ebosio@worldbank.org

Simeon Djankov

London School of Economics

and Political Science

Houghton Street

London

WC2A 2AE

s.djankov@lse.ac.uk
Edward L. Glaeser

Department of Economics

315A Littauer Center

Harvard University

Cambridge, MA 02138

and NBER

eglaeser@harvard.edu

Andrei Shleifer

Department of Economics

Harvard University

Littauer Center M-9

Cambridge, MA 02138

and NBER

ashleifer@harvard.edu 


\section{Introduction}

The world spent \$11 trillion on public procurement in 2018, amounting to 12 percent of global GDP (Figure 1). Public procurement's share of GDP typically rises with per capita income and represents more than one-tenth of national output for all rich countries, including 24 percent in Switzerland, 21 percent in the Netherlands, and 18 percent in Hong Kong and Singapore. Governments everywhere purchase vast amounts of goods, services and public works from private firms, even in sectors such as healthcare and defense that are state-run.

Figure 1: Public Procurement as a Share of GDP.

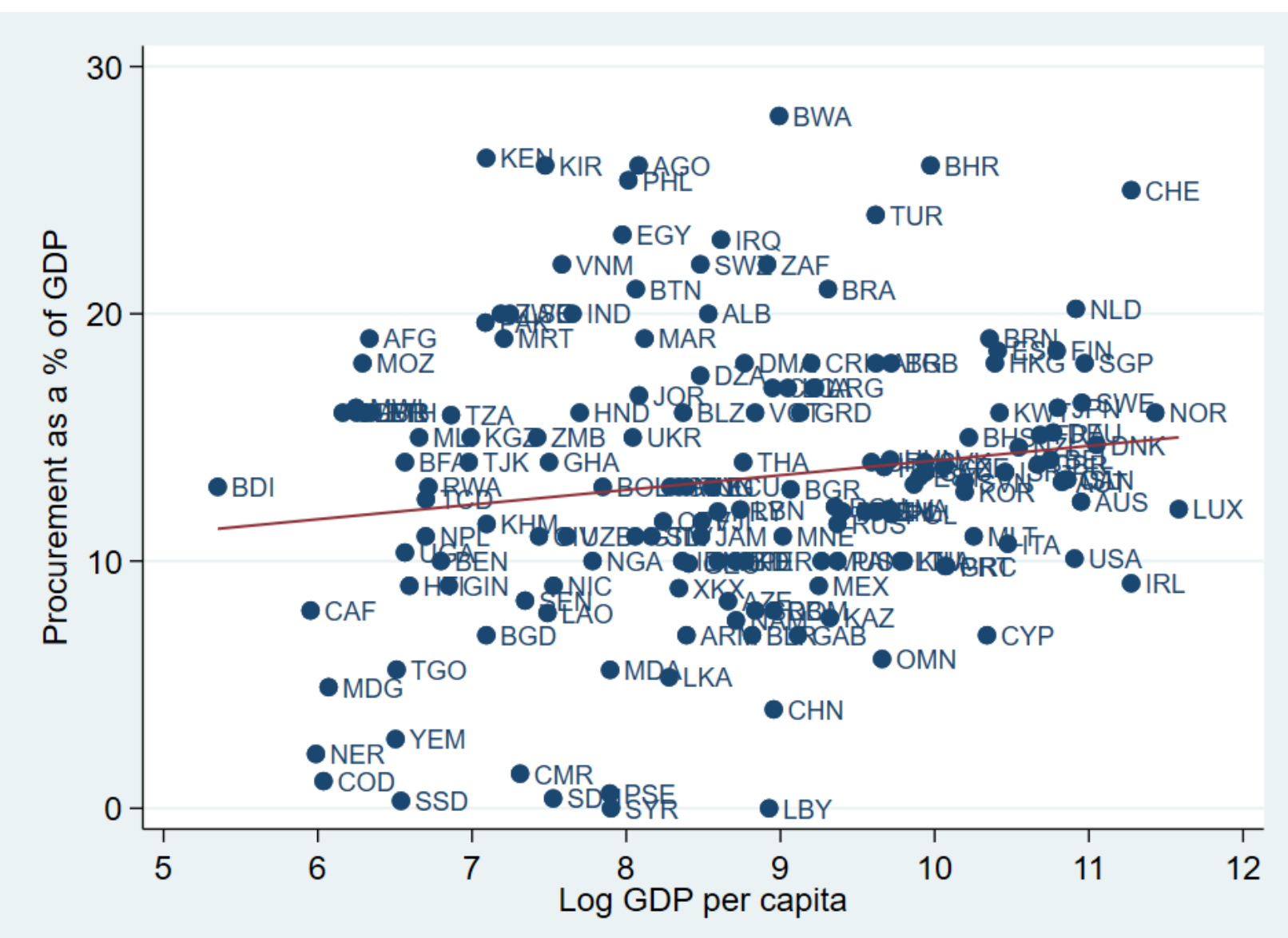

On the border between public and private sectors, procurement is particularly vulnerable to misconduct. Private companies have strong incentives to bribe public officials to increase payments, to cut out competitors, or to accept inferior quality. Procurement contracts face the same challenges of renegotiation and non-verifiable quality as bedevil private contracting (Hart and 
Moore 1988, Hart, Shleifer, and Vishny 1997). But unlike the private buyers, public agencies often lack the incentives and administrative capacity to handle these challenges.

The vulnerability of public buyers to private subversion has led every country to restrict the discretion of procuring entities in what they buy and pay. But while the regulation of the private sector empowers public officials and often enables them to extract bribes in exchange for regulatory relief (Djankov et al. 2003), the regulation of government constrains officials. Public procurement regulations reduce the discretion of buyers, typically with the intent of reducing corruption. But what do they really accomplish?

In this paper, we provide a panoramic overview of procurement laws and practices across 187 countries. As part of its Doing Business project, the World Bank administered a new module on procurement. Respondents in each of the countries (typically eight to twelve professionals ranging from public procurement lawyers to road construction companies and procuring entities) were presented with a hypothetical \$2.5 million road maintenance project. They were asked about the rules that would govern the procurement of such a project. Based on their answers, we construct measures of laws governing procurement, covering transparency, competition, exclusion of bidders, and integrity of contracts. Respondents also described whether and how procurement practices differed from the laws, so we can create corresponding measures of regulatory practice. In addition, respondents answered questions about the outcomes of the procurement process. These include typical problems in the Process of procurement, such as corruption, favoritism, collusion, and absence of competition, but also problems with the project itself - the Product of procurement -- including time delays, cost overruns, and low quality. In Section II, we describe the survey and how we aggregated the answers to create indices of regulation in law and practice, but also corruption and the quality of both Process and Product.

Section III presents several novel facts in these data. Countries that regulate one dimension of procurement are more likely to regulate others as well. Richer countries regulate procurement less than poorer ones by law, but have practices that are more restrictive on procurement entities than their laws. For example, poorer countries are more likely to have rules on running transparent auctions, while richer countries are more likely to actually run them. At the same time, laws do predict practice. For example, the correlation between transparency laws and practice is 0.67 . 
We focus on three outcomes from the survey: i) perceived corruption, ii) an index of Process covering favoritism, collusion, and absence of competition, and iii) an index of Product covering cost overruns, time delays, and low quality. The correlation coefficient between Process and Product is 0.60 . Corruption is associated with bad Process and Product. Richer and better governed countries have less corruption, and better Process and Product. The survey measures are also correlated with two external measures of road quality: the World Economic Forum's (WEF) survey question on the quality of roads in a country, and average speeds between major cities calculated by Google Maps. The correlation between Product and the WEF road quality measure is 0.45 (Figure 2). These measures of road quality also rise with income.

Figure 2: Correlation between Quality of Product and WEF Road Quality

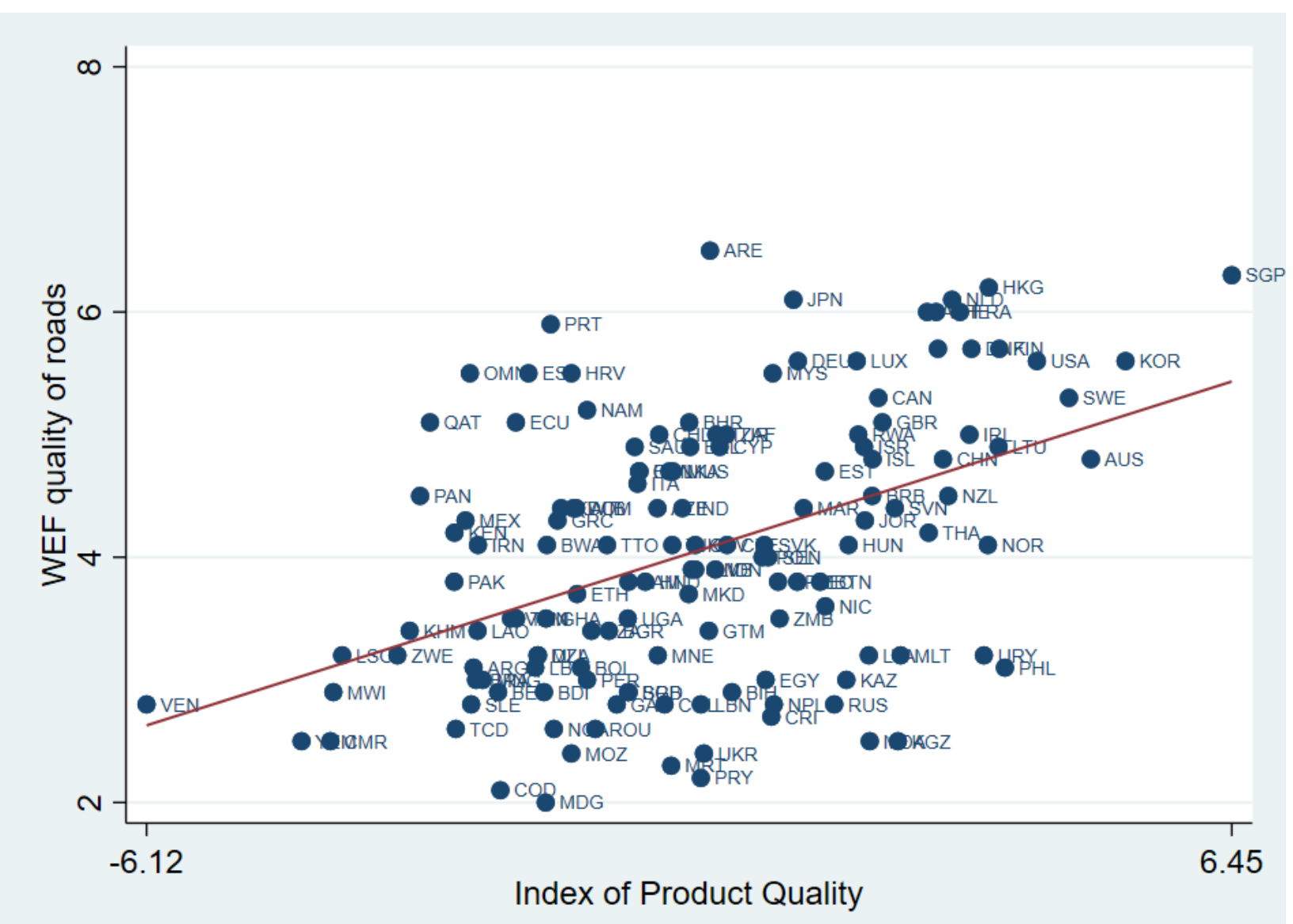

We then document that procurement practice is strongly positively correlated with Process and Product. Laws, however, are not. Section III raises a puzzle. Laws predict practice. Practice 
predicts outcomes. But laws do not predict outcomes. To understand these facts, Section IV proposes a model of regulation of public procurement we then use to make sense of the data.

The model considers a simple infrastructure procurement situation in which a Procuring Entity (PE) faces two bidders, with different costs and quality levels. One bidder is an Insider, who can engage in corrupt bargaining with the PE. The other bidder is an Outsider, who is bound by an external constraint not to bribe. We consider two institutional settings: regulation and discretion. Under regulation, the PE must run a second price auction and accept the low bid regardless of the quality level. Under discretion, the PE has the power to exclude a bidder on the basis of alleged lower quality. Quality is not, however, externally verifiable and this power enables the PE to exclude the higher quality Outsider in exchange for a bribe from the Insider.

We assume that the PE maximizes a weighted average of social welfare and bribes. The weight the PE places on social welfare is higher in countries with more accountable governments. We also assume that such governments increase the cost of bribing to the bidder. In a poorly governed country, it may be easy to just pay cash. In a better governed country, the bribes may take the form of gifts or favors valued by the PE at less than their cost.

In this model, the advantage of discretion is that it enables the PE to eliminate low quality bidders. The advantage of regulation is that it prevents the PE from excluding a high quality Outsider in exchange for a bribe from the Insider. When government effectiveness is high, discretion dominates regulation, because the PE only excludes low quality bidders from the auction. When it is low, regulation dominates discretion, because discretion leads to corruption.

The case for discretion becomes stronger when quality is endogenous, because the threat of exclusion stops bidders from cutting cost by cutting quality. In a sense, the regulated PE becomes a sitting duck for bidders who can game the fixed system. Nonetheless, when government effectiveness is low, regulation delivers higher social welfare than discretion.

We also consider theoretically an auction in which the PE chooses the level of transparency, subject to regulation. The PE may choose to be non-transparent (not inform outsiders about the auction) in exchange for a bribe to reduce competition. The model predicts that in well-governed countries, transparency will be high in practice even without regulation. In poorly-governed countries, transparency will be low in practice even with regulation. 
In Sections V and VI, we test four implications of the model. We first document that regulation of procurement is associated with less corruption. The raw correlation between procurement regulations and corruption is negative, and becomes stronger when we control for the level of GDP, human capital, or government effectiveness. Since procurement regulations are more prevalent in poor and poorly governed countries, failure to control for the level of development mutes the connection between laws and corruption. As the model predicts, procurement regulation is associated with less corruption in the procurement process.

We then examine the model's implication that practices are more restrictive than laws in high public sector capacity countries, and vice versa in low capacity ones. We measure the level of public sector capacity either with human capital or with a survey measure of government efficiency. We find that laws are typically more restrictive than practice in low human capital countries, and the reverse in high human capital ones.

In Section VI, we turn to the predictions for Process and Product. The model predicts that Process and Product improve with government effectiveness regardless of the laws on the books. This prediction clearly holds in the data. But the correlation between laws and these outcomes is negligible. This leads us to the model's main prediction that reconciles our findings: laws should be positively associated with outcomes in low effectiveness countries and negatively in high effectiveness ones. In fact, the univariate correlation between the laws index and the Product index is 0.30 in low human capital countries and -0.32 in high human capital ones.

We also test this prediction with continuous interactions between public sector capacity and laws. The interactions are statistically strong and economically meaningful. The interaction between laws and human capital has a significant correlation with all but one of the six components of the Product and Process indices. The correlation of laws with favoritism, low quality and cost overruns is always more negative in better educated countries, and statistically significant at the $1 \%$ level. The correlation of laws with time delay, collusion and lack of competition is also negative, but statistically insignificant at conventional levels.

Section VII concludes. Procuring entities are typically highly regulated, but while these regulations are associated with less corruption, they are not associated with improvements along other dimensions. That presents a puzzle because laws predict practice and practice predicts 
outcomes, but laws do not predict outcomes. The resolution of this puzzle is that the overall relationship between laws and outcomes misses critical heterogeneity. Laws improve outcomes when public sector capacity is low, and harm outcomes when public sector capacity is high. As a result, regulation of procurement helps, but only in poor countries.

\section{Literature Review}

This paper contributes to several strands of a large literature on government procurement and performance. Public procurement has been found to suffer from bid rigging (Porter and Zona 1993, Conley and Decarolis 2016), cost overruns (Flyvbjerg 2003), favoritism towards politically connected bidders (Burgess et al. 2015, Mironov and Zhuravskaya 2016, Baranek and Titl 2020), lack of transparency (Coviello and Galiarducci 2014), collusion between politicians and firms (Coviello and Gagliarducci 2017), and simply bad choices (Bandiera et al. 2009). Corruption has also been found to be common in procurement (DiTella and Schargrodsky 2003, Olken 2007, Collier et al. 2015, Colonnelli and Prem 2020, and Lichand and Fernades 2019), particularly when contracts are renegotiated (Huysentrust 2001, Decarolis 2014, Decarolis and Palumbo 2015, and Campos et al. 2019). Our data addresses the prevalence of cost overruns, favoritism, collusion, and corruption in procurement. We also measure renegotiation.

The tradeoff between rules and discretion has been a central topic of research on procurement. Kelman’s (1990, 2002) early work stressed the costs of rigid regulations in the U.S. government procurement, and made the case for discretion. More recently, research on the potential benefits of discretion has progressed rapidly (Spagnolo 2012, Szucs 2017, Coviello et al. 2018, Rasul and Rogger 2018, Best et al. 2019, Bandiera et al. 2020, Decarolis et al. 2020a, and Decarolis et al. 2020b). Our paper does not have the compelling sources of exogenous variation found in these studies, but our geographic and theoretical focus is broader, as we cover 187 countries and the complete path of the procurement process.

We also follow the broad literature that connects the quality of government with human capital, education, and other characteristics across countries (Barro 1999, La Porta et al. 1999, Milligan et al 2004, Barro and McCleary, 2005, Glaeser, Ponzetto, and Shleifer 2007, Pande 2011, Barro 2013, Botero et al 2013, Decarolis et al. 2019). The interaction between the quality of government employees and the benefits of regulating them is a central theme of this paper. 
Our paper is most closely linked to the literature that gave birth to the Doing Business Report, which examines regulation around the world (Djankov et al 2002, Djankov et al 2003a,b, Botero et al 2004, and Djankov et al 2008a,b). We build on this work by focusing on the regulation of government rather than that of the private sector. The factors that shape the regulation of government are different from those shaping the regulation of the private economy.

Lastly, our paper contributes to the literature on corruption. The theoretical studies have focused on the determinants for corrupt behavior (Banfield 1975, Shleifer and Vishny 1993). Empirical studies have focused on the magnitude of corruption (Svensson 2003, Sequiera and Djankov 2014, Olken et al 2018), political connections as channels for corruption (Fisman 2001 and Faccio 2006), transparency of politicians’ incomes as a barrier to corruption (Djankov et al 2010, Banerjee et al 2012), or administrative design to reduce bribes (Bertrand et al 2007, Duflo et al 2012). We show that corruption is reduced by regulatory constraints on the behavior of procuring entities both by law and in practice.

\section{Data}

\section{The Case Study}

The analysis in this paper is based on a new World Bank dataset which describes the regulation of public procurement in 187 countries in 2019. This section describes the survey (including its respondents) and the variables we use in the empirical analysis. Our analysis is based on a fictitious case study of a government agency procuring road resurfacing works. The type of road works was determined through an empirical study of road-related projects completed by the World Bank over the last twenty years, also known as Road Cost Knowledge System (ROCKS). We use the ROCKS database to motivate our case facts. ${ }^{2}$

The survey respondents are presented with detailed assumptions on the contract, the road, the procuring entity $(\mathrm{PE})$, the bidder, and the procurement process. The contract entails the

\footnotetext{
${ }^{2}$ Overall, 1,800 projects covering 89 countries are documented in the ROCKS database. It covers the initial product documents for each project, various interim progress reports, the completion report, the procured and contracted amount and time commitment, as well as the actual time and cost spent on completing the project (Bosio et al., 2018).
} 
resurfacing of $20 \mathrm{~km}$ of a two-lane flat road with an asphalt overlay of 40 to $59 \mathrm{~mm}$ (or its most common equivalent in the country). The road connects the economy's largest business city to another city within the same state, region or province. The road is not a highway, nor is it operated under concession. The value of the contract is $\$ 2,500,000$ and the contract does not include any other work. This represents the median value of road resurfacing contracts documented in the World Bank’s ROCKS database (Bosio et al. 2018), and we take it to be representative of the typical public road works contract around the world. ${ }^{3}$

The PE choosing the contractor for this project is a government agency, typically the Ministry of Transportation, and is the sole financer of the works. To make the case study comparable across countries, the contract is assumed to be tendered through an open, unrestricted, and competitive public call for tenders. The process ends with the contract awarded to BidCo, a firm whose bid satisfies all technical and administrative criteria. BidCo is a privately and domestically-owned medium sized Limited Liability Company (or its most common legal equivalent). BidCo operates in the economy’s largest business city, is in good standing with all relevant authorities, and has all the licenses and permits required to operate. BidCo is registered with the PE and has already participated in similar bidding processes in the past 5 years.

The hypothetical contract abstracts from a number of issues important in public procurement. First, it focuses exclusively on procurement of works and excludes the procurement of services and goods. Second, we do not allow for the road to be a highway, to exclude roads operated under concession. Third, we do not allow for the road to be a street within the boundaries of a city, because many cities around the world would not conduct open tendering for such a contract, but rather carry out this maintenance in-house or through direct award. Fourth, we assume that the value of the contract is $\$ 2,500,000$ and only examine the rules that apply to the open tendering of a contract of such value. ${ }^{4}$ Fifth, our data underestimates the complexity of public procurement by assuming that the works are procured through an open tendering procedure, i.e. a

\footnotetext{
${ }^{3}$ One may wonder whether $\$ 2.5$ million is too low a cutoff for rich countries. Among the 37 OECD members, 20 have no regulatory thresholds or thresholds below $\$ 2.5$ million, and the remaining 17 have higher thresholds at which somewhat more onerous rules apply. On net we think having a fixed size project everywhere is preferred.

${ }^{4}$ In countries that are members of the European Union, this contract is below the threshold of $€ 5,350,000$ for the applicability of the EU Directive 2014/24/EU on public procurement.
} 
competitive procedure in which any qualified company can submit an economic offer. All other types of procurement, including direct award, framework agreements, negotiated procedures, restricted tendering, etc. are excluded by design. Sixth, BidCo has already worked with the PE and has already participated in similar bidding processes in the past 5 years. This assumption eliminates the pre-registration process common in many countries.

\section{The Questionnaire}

The data on the road resurfacing case study was collected in two rounds - in 2018 and 2019 through questionnaires disseminated to 190 countries. Three countries (Libya, the Maldives, and Syria) have not completed an open tendering procurement procedure for road works in the past 5 years and are excluded from the analysis. The final sample includes 187 economies: 58 highincome, 53 upper-middle-income, and 76 low and lower-middle-income countries.

The questionnaire was completed by over 1,200 professionals involved in the procurement activity, including (1) lawyers; (2) construction and engineering firms; and (3) procuring entities. Whenever possible, we compared the answers from people in the same country and collected all the pertinent legal documents that the respondents identified. Lawyers answered primarily questions related to the legal framework. Construction and engineering firms answered questions about practice, focusing on the actual application of public procurement regulation. These experts were also essential for us to understand phases of the project in which lawyers are less involved (such as quality control, inspections and payments). PE's reported on both laws and practice. The World Bank team then contacted different respondents in a country to reconcile their answers, which sometimes differed because of misunderstandings.

The questionnaire provided to these respondents was divided into 4 parts, following the four main chronological stages of the typical public procurement process (Figure 3). Across all parts, respondents are presented with 4 types of requests: (1) to indicate which rules regulate each stage of public procurement; (2) to outline the procedures that would be followed in the award and execution of a contract for the resurfacing of a flat two-lane road; (3) to indicate how long each of these procedures would take; and (4) multiple-choice questions on the frequency of certain occurrences in public procurement, such as collusion or bribery. 
Figure 3: Chronological evolution of the public procurement process.
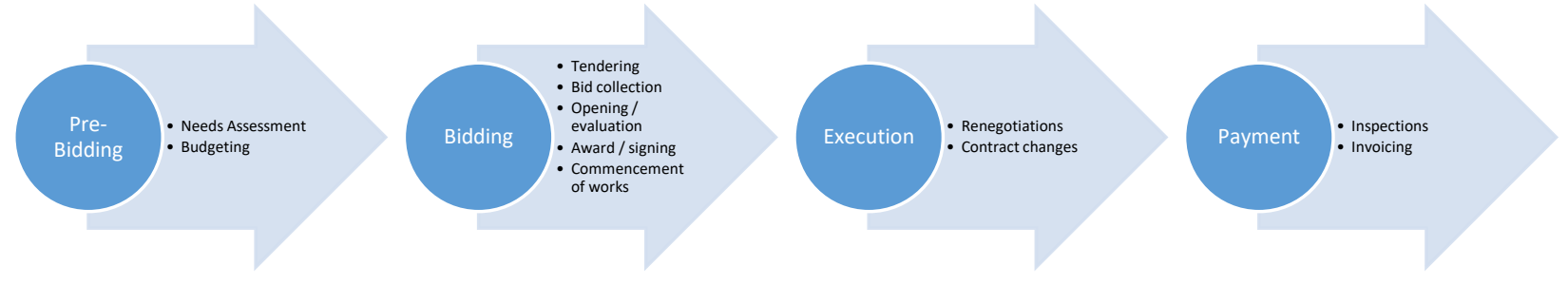

The pre-bidding stage describes the administrative process that the PE goes through to identify its procurement needs and secure the related funds. Respondents are asked to indicate how the contract value is normally estimated, and whether it is published in the tender documents. We also ask whether the PE needs to set aside all necessary funds before advertising the opportunity or can do so without having secured the budget.

The bidding stage describes how the procurement method is chosen, how the information related to the tender is made publicly available and how bids are collected from the private sector. Within this stage, the bid opening, evaluation and contract signing phases concern the criteria used to evaluate bids and award the contract. Respondents are asked which procurement method would most commonly be used for a routine contract for road resurfacing, and whether price would be the most common criterion for the award of such contract. They also describe how the process would evolve and the most common sources of delay.

The execution stage describes the procedures from when the contractor receives a notice to proceed until when the works are completed, including requirements on contract amendments. Respondents estimate how often, and by how long, the execution of the contract is delayed by changes in contract terms resulting from contract renegotiations or additional works requests. They also indicate the laws that regulate sub-contracting and the disclosure requirements on BidCo if it decides to subcontract part of the works during the life of the contract.

Finally, the payment stage measures the law and practices around the timeliness and frequency of payments. Respondents estimate the frequency of inspections and how often disagreements on such inspections would delay the execution process. Respondents provide an estimate of how long it takes to collect payment from the procuring entity. 
The questionnaire is organized chronologically to facilitate the respondents' thinking about the public procurement process. However, the questions are organized around four main themes: (1) transparency; (2) competition; (3) limits to exclusion; and (4) integrity of contract. Questions on transparency ask about the level of public availability of key documents. Questions on competition ask which rules are in place to broaden participation in the tendering process. Questions on the limits to exclusion ask whether there are rules in place making it more difficult for the PE to exclude bidders without justifying the exclusion or publishing the reasons. Finally, questions on the integrity of the contract ask about events that may take place during the life of the contract, including payment, the ability to add subcontractors, renegotiation after the contract is signed, as well as change in project specifications (Table 1). Appendix A describes the construction of all the variables in detail, and presents many illustrations and examples.

Table 1: Explanatory Variables, By Law and In Practice

\begin{tabular}{|c|c|}
\hline \multicolumn{2}{|c|}{ TRANSPARENCY } \\
\hline LAW & PRACTICE \\
\hline $\begin{array}{l}\text { By law, do procurement plans need to be made publicly } \\
\text { available by the Procuring Entity? }\end{array}$ & $\begin{array}{l}\text { In practice, are procurement plans made publicly } \\
\text { available by the Procuring Entity? }\end{array}$ \\
\hline $\begin{array}{l}\text { By law, do model procurement documents and materials } \\
\text { / standard contract conditions need to be made publicly } \\
\text { available by the Procuring Entity? }\end{array}$ & $\begin{array}{l}\text { In practice, are model procurement documents and } \\
\text { materials / standard contract conditions made publicly } \\
\text { available by the Procuring Entity? }\end{array}$ \\
\hline $\begin{array}{l}\text { By law, do tender notices need to be made publicly } \\
\text { available by the Procuring Entity? }\end{array}$ & $\begin{array}{l}\text { In practice, are tender notices made publicly available } \\
\text { by the Procuring Entity? }\end{array}$ \\
\hline $\begin{array}{l}\text { By law, do tender documents and technical } \\
\text { specifications need to be made publicly available by the } \\
\text { Procuring Entity? }\end{array}$ & $\begin{array}{l}\text { In practice, are tender documents and technical } \\
\text { specifications made publicly available by the Procuring } \\
\text { Entity? }\end{array}$ \\
\hline $\begin{array}{l}\text { By law, do notices of award / bidding results need to be } \\
\text { made publicly available by the Procuring Entity? }\end{array}$ & $\begin{array}{l}\text { In practice, are notices of award / bidding results made } \\
\text { publicly available by the Procuring Entity? }\end{array}$ \\
\hline $\begin{array}{l}\text { By law, does the contract need to be made publicly } \\
\text { available by the Procuring Entity? }\end{array}$ & $\begin{array}{l}\text { In practice, are contracts made publicly available by the } \\
\text { Procuring Entity? }\end{array}$ \\
\hline $\begin{array}{l}\text { By law, does the legal framework regulate the need to } \\
\text { make contract renegotiations publicly available? }\end{array}$ & $\begin{array}{l}\text { In practice, are the results of contract renegotiations } \\
\text { made publicly available? }\end{array}$ \\
\hline \multicolumn{2}{|c|}{ COMPETITION } \\
\hline LAW & PRACTICE \\
\hline $\begin{array}{l}\text { According to the legal framework, is open tendering the } \\
\text { default method of procurement for a contract like the } \\
\text { one described in our case study? }\end{array}$ & $\begin{array}{l}\text { In practice, is open tendering the most common method } \\
\text { of procurement for a contract like the one described in } \\
\text { our case study? }\end{array}$ \\
\hline $\begin{array}{l}\text { According to the legal framework, after the } \\
\text { advertisement of an open tendering procedure, can the } \\
\text { Procuring Entity require bidders to participate in a } \\
\text { prequalification process before submitting an economic } \\
\text { offer? }\end{array}$ & $\begin{array}{l}\text { In practice, does the Procuring Entity avoid requiring } \\
\text { bidders to participate in a prequalification process? }\end{array}$ \\
\hline
\end{tabular}


Does the legal framework prohibit dividing contracts to circumvent thresholds for open tendering?

In practice, does the Procuring Entity avoid dividing contracts to circumvent thresholds for open tendering?

According to the legal framework, is there a minimum time limit between the advertisement of the tender notice and the submission deadline for an open tendering procedure like the one described in our case study?

Does the legal framework require the Procuring Entity to proceed to bid opening immediately after the deadline for bid submission has been reached?

Is there a standstill (or pause) period between public notice of award and contract signing to allow unsuccessful bidders to challenge the award decision that suspends the procurement process?

\section{LIMITS TO EXCLUSION}

\begin{tabular}{l|l}
\multicolumn{1}{c|}{ LAW } & \multicolumn{1}{c}{ PRACTICE } \\
\hline $\begin{array}{l}\text { Does the legal framework establish the minimum } \\
\text { content of the tender notice and tender documents? }\end{array}$ & $\begin{array}{l}\text { In practice, does the Procuring Entity avoid defining } \\
\text { technical specifications to benefit a specific bidder? }\end{array}$ \\
\hline $\begin{array}{l}\text { Is the Procuring Entity required to make clarifications } \\
\text { provided to bidders publicly available? }\end{array}$ & $\begin{array}{l}\text { In practice, does the PE avoid informal meetings with } \\
\text { individual bidders? }\end{array}$ \\
\hline $\begin{array}{l}\text { According to the legal framework, is price the award } \\
\text { criterion to be used by the Procuring Entity for a } \\
\text { contract like the one described in our case study? }\end{array}$ & $\begin{array}{l}\text { In practice, does the PE keep the award criterion } \\
\text { unchanged after the bids are opened? }\end{array}$ \\
$\begin{array}{l}\text { Does the legal framework establish a criterion to } \\
\text { identify abnormally low bids? }\end{array}$ & $\begin{array}{l}\text { In practice, is it rare that bidders submit recklessly low } \\
\text { bids to win the tender? }\end{array}$ \\
\hline $\begin{array}{l}\text { Does the legal framework define what constitutes a non- } \\
\text { substantial error? }\end{array}$ & $\begin{array}{l}\text { In practice, if a bidder submits a bid with a non- } \\
\text { substantial error, is it given the opportunity to rectify } \\
\text { such error before disqualification? }\end{array}$ \\
\hline
\end{tabular}

INTEGRITY of CONTRACT

\begin{tabular}{l|l} 
LAW & PRACTICE
\end{tabular}

Is the Procuring Entity required to have already allocated budget to a specific project before tendering?

Does the law regulate the selection, disclosure and liability of subcontractors?

In an open tendering procedure, does the Procuring Entity award a contract after having already set aside all the necessary funds?

Does the Procuring Entity avoid employing subcontractors that were neither properly selected nor disclosed during the tender process?

By law, can additional works be procured through direct award?

In practice, is the usage of direct awards to procure additional works avoided?

Does the law regulate the scope, limits and disclosure of contract renegotiations?

Does the Procuring Entity avoid using the renegotiation process to increase the price or the scope of the project without another competitive process?

During the execution of the contract, does the legal framework establish a timeframe within which the Procuring Entity must process the payment once an invoice is received?

According to the legal framework, is the company entitled to claim interest on late payments if the Procuring Entity does not pay within the legally established timeframe?

In practice, does BidCo receive payment within the timeframe established by the legal framework?

In practice, does BidCo receive interest on late payment? 
A central feature of our design is to ask questions about both the laws regulating procurement and its actual practice. The laws questions elicit mandatory rules in each country as the process moves along. These questions describe the ways in which the regulations reduce the discretion of the PE. The "practice" questions mirror the "law" questions and are used to gauge the actual application of the law. The coding of practice parallels that of laws: the less discretion the PE exercises in reality, the higher is the practice score.

As an example, the questionnaire asks whether, by law, the $\mathrm{PE}$ is required to publish tender notices and documents online. The corresponding "practice" questions ask whether these notices and documents are indeed published. If such publication is meant to be online, the team checks whether this happens. Other practice questions measure the frequency of applying a particular provision in the law. For example, the questionnaire asks whether, by law, open tendering is the default method of procurement. The mirror practice question inquires how often open tendering is used to procure road resurfacing works.

The regulation index mirrors the four themes around which the questionnaire is organized: transparency, competition, limits to exclusion, and integrity of contract. The Law and Practice indices are sums of their four sub-indices (Transparency, Competition, Limits to Exclusion, and Integrity of Contract) and vary between 0 and 4, with higher values representing more regulation or less discretionary practice. On the Laws index, Greece scores highest (3 out of possible 4), followed by Rwanda (2.98), Italy, and Latvia (both at 2.92). At the other end, Israel scores 0.31, followed by Kiribati (0.45). On the Practice index, Estonia scores highest with 3.55, followed by Slovenia (3.52) and Hong Kong (3.40). At the other end, Palau only scores 0.20, followed by Myanmar and South Sudan at 0.31 .

The questionnaire also elicits expert opinions about outcomes. We convert these answers into three outcome variables (Table 2), whose construction is also described in Appendix A: corruption, Product, and Process. The question for corruption in procurement asks how often private sector companies resort to informal payments in return for help from public officials in circumventing public procurement rules. Product quality in the procurement context reflects the time to completion, cost overruns, and the low quality of actual works. The efficiency of Process 
covers favoritism, collusion, and the absence of competition in procurement. Notice that we code the inputs into the measures of outcomes literally, so higher scores refer to worse outcomes (e.g., more corruption, longer delays, higher cost overruns). However, we reverse the signs on the aggregate outcome measures, so higher scores reflect better Product and Process.

Table 2: Outcome Variables, Corruption, Quality of Product, Efficiency of Process

\begin{tabular}{|c|c|c|c|c|c|}
\hline \multicolumn{2}{|r|}{ Corruption } & \multicolumn{2}{|r|}{ Quality of product } & \multicolumn{2}{|r|}{ Efficiency of process } \\
\hline \multirow{3}{*}{ Bribes } & \multirow{3}{*}{$\begin{array}{l}\text { How often do private sector } \\
\text { companies informally pay } \\
\text { public officials to circumvent } \\
\text { public procurement rules? }\end{array}$} & Time & $\begin{array}{l}\text { The time that it takes in calendar } \\
\text { days from the moment the } \\
\text { procuring entity decides to } \\
\text { procure road works until the } \\
\text { winning bidder can commence } \\
\text { the works as well as the delays } \\
\text { associated with contract } \\
\text { management. }\end{array}$ & Favoritism & $\begin{array}{l}\text { How often do procuring entities } \\
\text { circumvent public procurement } \\
\text { rules by interpreting selection } \\
\text { criteria in a way that favors a } \\
\text { specific bidder? }\end{array}$ \\
\hline & & Overruns & $\begin{array}{l}\text { How often are the works } \\
\text { delivered within the original } \\
\text { budget? }\end{array}$ & Collusion & $\begin{array}{l}\text { How often do private sector } \\
\text { companies collude with the } \\
\text { Procuring Entity, to negate market } \\
\text { entry to other competitors? }\end{array}$ \\
\hline & & $\begin{array}{l}\text { Low } \\
\text { quality }\end{array}$ & $\begin{array}{l}\text { How often do private sector } \\
\text { companies execute the contract } \\
\text { with less quality or with } \\
\text { different technical specifications } \\
\text { than were submitted during the } \\
\text { tender process? }\end{array}$ & $\begin{array}{l}\text { No } \\
\text { competition }\end{array}$ & $\begin{array}{l}\text { How often do procuring entities } \\
\text { use non-competitive procurement } \\
\text { methods instead of open tendering } \\
\text { to restrict market entry? }\end{array}$ \\
\hline
\end{tabular}

The scoring of outcomes leads to an unsurprising list of best and worst countries. On corruption, the worst are Burundi, Cameroon, and Ivory Coast, and the best are Australia, Canada, and Finland. On Product, the worst are Venezuela, Haiti, and Timor Leste, and the best are Singapore, Korea, and Australia. On Process, the worst are Niger, Lao, and Myanmar, and the best are Germany, Denmark, and Norway. We next turn to a more formal analysis.

\section{Correlations in the Data}

In this section, we examine four broad aspects of the data. First, what are the patterns in the laws governing public procurement? These include transparency, competition, exclusion, and integrity of contract, as well as an overall regulation index. Do countries that score high on one element of these regulations also perform well on others? Do these laws vary systematically with the level of economic development? Second, what are the corresponding facts about practice? Are practices for different aspects of procurement regulation correlated with each other, and how do 
they vary with per capita GDP? Third, are laws correlated with practices? In principle one can imagine that countries ignore the laws and have a laxer and more discretionary practice of procurement, or alternatively that countries in practice introduce constraints that are not mandated by the law. Fourth, how our measured procurement outcomes -- corruption, Process, and Product -- vary with laws and practice, but also with the level of development?

\section{The Structure of Laws and Practice}

Table 3 presents the correlations between the four measures of regulation of procurement, the laws index, and the log of per capita income. Across countries, different aspects of regulation of procurement are strongly positively correlated with each other. But we also get the first surprising result: regulation is generally less restrictive in richer countries: the correlation coefficient with per capita income is -0.217 , so richer countries give their PE's more discretion. They are particularly prone to have fewer laws regulating competition and integrity of contract.

Table 3: Correlations Between Components of the Law Index

\begin{tabular}{|l|l|l|l|l|l|l|}
\hline & $\begin{array}{c}\text { Transparency } \\
\text { Laws }\end{array}$ & $\begin{array}{c}\text { Competition } \\
\text { Laws }\end{array}$ & $\begin{array}{c}\text { Integrity of } \\
\text { Contract Laws }\end{array}$ & $\begin{array}{c}\text { Limits to Exclusion } \\
\text { Laws }\end{array}$ & Log GDP & Laws \\
\hline Transparency Laws & 1.000 & & & & & \\
\hline Competition Laws & $0.502^{* * *}$ & 1.000 & & & & \\
\hline Integrity of Contract Laws & $0.502^{* * *}$ & $0.513^{* * *}$ & 1.000 & & & \\
\hline Limits to Exclusion Laws & $0.251^{* * *}$ & $0.121^{*}$ & $0.223^{* * *}$ & 1.000 & & \\
\hline Log GDP & -0.0824 & $-0.322^{* * *}$ & $-0.237^{* * *}$ & 0.0590 & 1.000 & \\
\hline Laws & $0.784^{* * *}$ & $0.749^{* * *}$ & $0.824^{* * *}$ & $0.502^{* * *}$ & $-0.217^{* * *}$ & 1.000 \\
\hline
\end{tabular}

Table 4 shows that practices across multiple dimensions of procurement regulation are highly positively correlated with each other. We also find that practices are less discretionary in richer countries, with correlation coefficient of 0.445 - the opposite of the finding for laws.

Table 4: Correlations Between Components of the Practice Index

\begin{tabular}{|l|l|l|l|l|l|l|}
\hline & $\begin{array}{c}\text { Transparency } \\
\text { Practice }\end{array}$ & \multicolumn{1}{|c|}{$\begin{array}{c}\text { Competition } \\
\text { Practice }\end{array}$} & $\begin{array}{c}\text { Limits to } \\
\text { Exclusion } \\
\text { Practice }\end{array}$ & $\begin{array}{c}\text { Integrity of } \\
\text { Contract Practice }\end{array}$ & Log GDP & Practice \\
\hline Transparency Practice & 1.000 & & & & & \\
\hline Competition Practice & $0.399^{* * *}$ & 1.000 & & & & \\
\hline Limits to Exclusion Practice & 0.0486 & $0.197^{* * *}$ & 1.000 & & & \\
\hline Integrity of Contract Practice & $0.177^{* *}$ & $0.293^{* * *}$ & $0.586^{* * *}$ & 1.000 & & \\
\hline Log GDP & $0.170^{* *}$ & $0.189^{* * *}$ & $0.417^{* * *}$ & $0.438^{* * *}$ & 1.000 & \\
\hline Practice & $0.604^{* * *}$ & $0.687^{* * *}$ & $0.694^{* * *}$ & $0.730^{* * *}$ & $0.445^{* * *}$ & 1.000 \\
\hline
\end{tabular}


Figure 4 shows that procurement laws and practice are correlated across countries. Going a step further, if we regress practices on laws and logGDP, we find

$$
\text { Practice }=\frac{.46}{(.07)} \cdot \operatorname{Laws}+\frac{.26}{(.03)} \cdot \log (G D P)-\frac{1.21}{(.31)}
$$

There are 187 observations and the r-squared is .36. Both income and laws have a large role in explaining the variation of regulatory practice across countries. The relationship between laws and practice holds not only for the overall regulatory index, but also for its Transparency and Competition components, as illustrated in Table 5.

Figure 4: Procurement Law and Practice Are Correlated

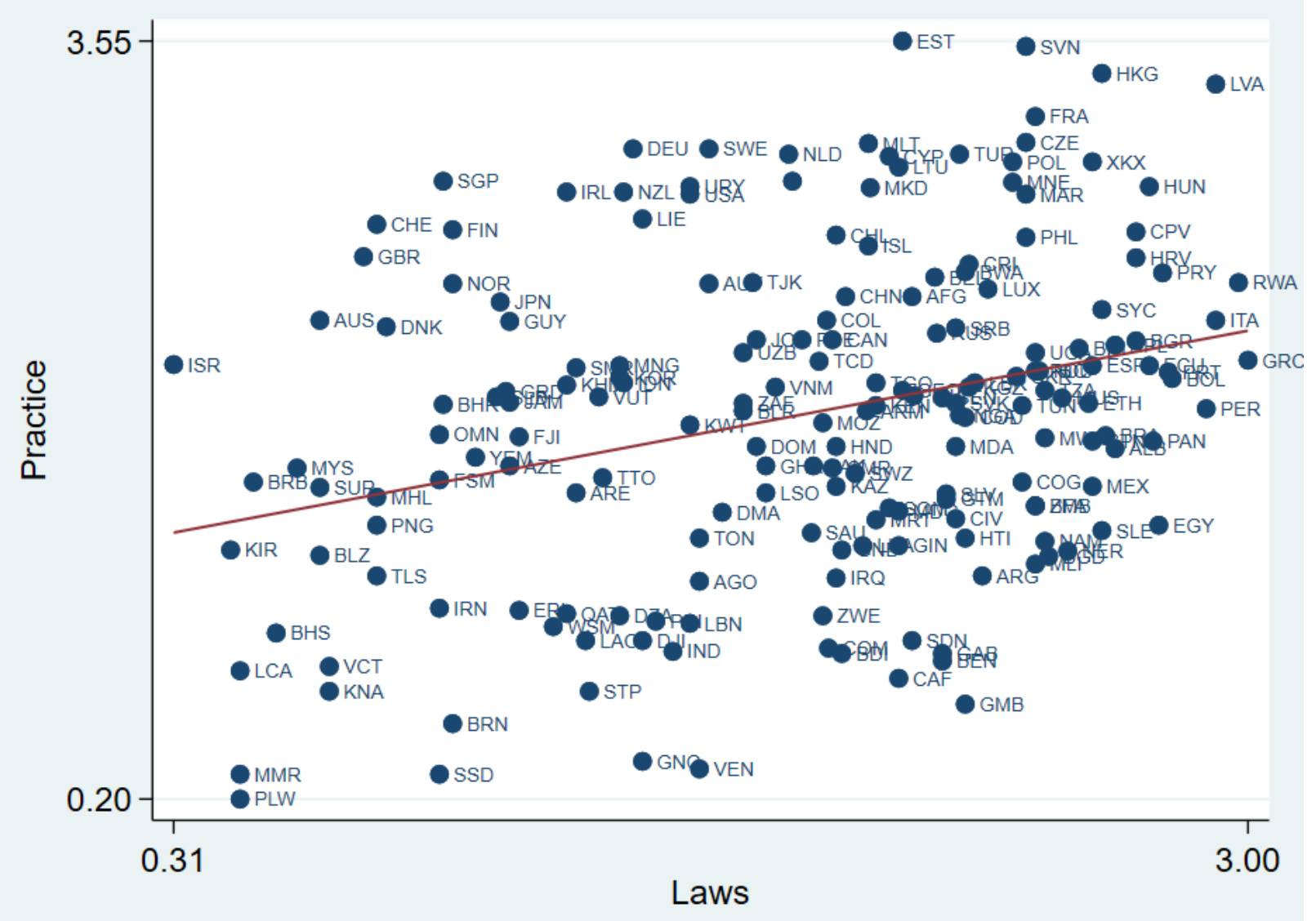


Table 5: Correlations between Components of the Law and Practice Indices

\begin{tabular}{|l|c|c|c|c|}
\hline & $\begin{array}{c}\text { Transparency } \\
\text { Practice }\end{array}$ & $\begin{array}{c}\text { Competition } \\
\text { Practice }\end{array}$ & $\begin{array}{c}\text { Limits to } \\
\text { Exclusion Practice }\end{array}$ & $\begin{array}{c}\text { Integrity of } \\
\text { Contract Practice }\end{array}$ \\
\hline Transparency Laws & $\begin{array}{c}0.875^{* * *} \\
(0.066)\end{array}$ & & & \\
\hline Competition Laws & & $0.619^{* * *}$ & & \\
\hline Limits to Exclusion Laws & & $(0.080)$ & 0.0702 \\
$(0.110)$ & \\
\hline Integrity of Contract Laws & & & & 0.077 \\
\hline Log GDP & $0.043^{* * *}$ & $0.062^{* * *}$ & $0.086^{* * *}$ & $0.054)$ \\
\hline $\mathrm{R}^{2}$ & $(0.010)$ & $(0.012)$ & $(0.014)$ & $(0.010)$ \\
\hline $\mathrm{N}$ & 0.505 & 0.274 & 0.176 & 0.201 \\
\hline
\end{tabular}

\section{Outcomes}

The survey delivers three procurement related outcomes: corruption, Process, and Product. Figure 5 shows the relation between Product and Process. Table 6 presents the correlations between these three outcomes as well as with log per capita GDP and two external variables: the World Economic Forum survey measure of road quality and the average speed between major cities from Google Maps. The three outcomes are highly correlated with each other across countries, and they are all better in richer countries. The two external measures of road quality are also highly correlated with our survey measures and with national income.

Are these outcomes correlated with the laws and practice of procurement regulation? Table 7 shows the correlations between corruption, Process, and Product for both laws (odd columns) and practice (even columns). Corruption is negatively correlated with both laws and practice, but the correlation with practices is stronger. Both Process and Product are robustly positively correlated with all the practice variables. In contrast, the correlations with the laws variable are weak, and often negative: countries with more legal controls of PE's have no better and perhaps worse outcomes.

Table 6: Correlations between Outcome Variables and Income per Capita

\begin{tabular}{|l|l|l|l|l|l|l|}
\hline & $\begin{array}{c}\text { Efficiency of } \\
\text { Process }\end{array}$ & $\begin{array}{c}\text { Quality of } \\
\text { Product }\end{array}$ & Corruption & Road Quality & Aspeed & Log GDP \\
\hline Efficiency of Process & 1 & & & & & \\
\hline Quality of Product & $0.597 * * *$ & 1 & & & & \\
\hline
\end{tabular}




\begin{tabular}{|l|l|l|l|l|l|l|}
\hline Corruption & $-0.550^{* * *}$ & $-0.565^{* * *}$ & 1 & & & \\
\hline Road Quality & $0.327^{* * *}$ & $0.454^{* * *}$ & $-0.464^{* * *}$ & 1 & & \\
\hline Aspeed & $0.177^{* *}$ & $0.191^{* *}$ & $-0.316^{* * *}$ & $0.370^{* * *}$ & 1 & \\
\hline Log GDP & $0.455^{* * *}$ & $0.534^{* * *}$ & $-0.669^{* * *}$ & $0.688^{* * *}$ & $0.496^{* * *}$ & 1 \\
\hline
\end{tabular}

Table 7: Correlations between Law and Practice and Outcome Variables

\begin{tabular}{|l|c|c|c|c|c|c|}
\hline & $\begin{array}{c}\text { Corruption } \\
\text { and Laws }\end{array}$ & $\begin{array}{c}\text { Corruption } \\
\text { and Practice }\end{array}$ & $\begin{array}{c}\text { Efficiency } \\
\text { of Process } \\
\text { and Laws }\end{array}$ & $\begin{array}{c}\text { Efficiency } \\
\text { of Process } \\
\text { and Practice }\end{array}$ & $\begin{array}{c}\text { Quality } \\
\text { of Product } \\
\text { and Laws }\end{array}$ & $\begin{array}{c}\text { Quality } \\
\text { of Product } \\
\text { and Practice }\end{array}$ \\
\hline Overall Index & -0.115 & $-0.617^{* * *}$ & -0.092 & $0.471^{* * *}$ & -0.063 & $0.583^{* * *}$ \\
\hline Transparency & $-0.236^{* * *}$ & $-0.344^{* * *}$ & -0.026 & $0.130^{*}$ & 0.0294 & $0.258^{* * *}$ \\
\hline Competition & -0.044 & $-0.368^{* * *}$ & $-0.129^{*}$ & $0.182^{* *}$ & -0.075 & $0.203^{* * *}$ \\
\hline $\begin{array}{l}\text { Limits to } \\
\text { Exclusion }\end{array}$ & -0.078 & $-0.451^{* * *}$ & 0.030 & $0.475^{* * *}$ & 0.056 & $0.518^{* * *}$ \\
\hline $\begin{array}{l}\text { Integrity of } \\
\text { Contract }\end{array}$ & 0.009 & $-0.495^{* * *}$ & -0.117 & $0.498^{* * *}$ & $-0.152^{* *}$ & $0.619^{* * *}$ \\
\hline
\end{tabular}

Figure 5: Correlation between Quality of Product and Efficiency of Process

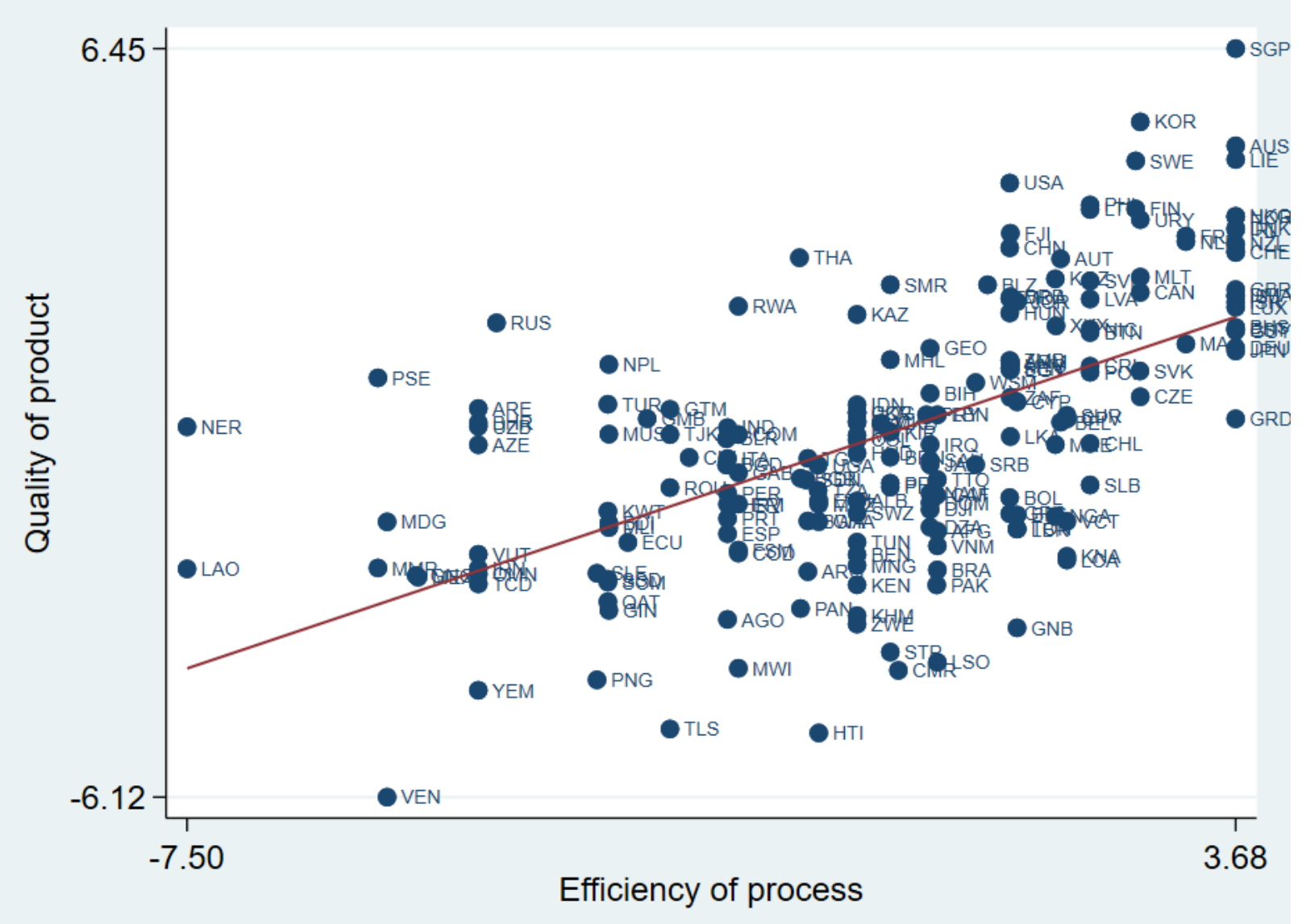


Table 8 presents these correlations for the components of Process and Product, looking only at the overall law and practice indexes. In every case, practice is negatively associated with these adverse outcomes. Laws, however, are not consistently associated with outcomes.

Table 8: Correlations between Law and Practice and Outcome Components

\begin{tabular}{|l|l|l|l|l|l|l|}
\hline & \multicolumn{1}{|c|}{ Favoritism } & \multicolumn{1}{|c}{ Collusion } & No Competition & \multicolumn{1}{|c|}{ Time } & Overrun & Low Quality \\
\hline Laws & $0.184^{* *}$ & 0.026 & 0.037 & -0.0621 & 0.077 & $0.138^{*}$ \\
\hline Practice & $-0.323^{* * *}$ & $-0.426^{* * *}$ & $-0.509^{* * *}$ & $-0.597^{* * *}$ & $-0.341^{* * *}$ & $-0.391^{* * *}$ \\
\hline
\end{tabular}

Corruption, Process, and Product all improve with income, and with better regulatory practice, but not with laws. These findings set up the central quandary of our paper. Laws strongly predict practice. Practice strongly predicts outcomes, including corruption, Process, and Product quality. Yet laws have very limited predictive power for outcomes. Starting with the theory in the next section, we seek to resolve this fundamental puzzle.

\section{A Model of Procurement}

We examine the impact of regulating a government buyer, the procurement entity (PE), on the procurement process, procurement outcomes, and corruption. Like our data, the model distinguishes laws governing procurement, which we see as restrictions on PE's discretion, from procurement practice, which need not coincide with laws.

A road can be built either by an "Insider" who has cost $K_{I}$ and delivers quality $Q_{I}$, or an “Outsider" with cost of $K_{O}$ and quality $Q_{O}$. The contractor is paid by the PE, and consumer surplus is defined as Quality - Payment. We assume that only the Insider can bribe the PE; the Outsider is either bound by external rules or is not in a relationship of trust with the PE. We define the PE's objective as $\alpha$ (Quality - Payment $)+$ Bribes, where Bribes refers to side-payments made by the Insider to the PE. The parameter $\alpha$ captures the extent to which the PE internalizes social welfare, which in turn reflect the quality of public institutions in a country.

We focus on a second price auction, which means that the bidder who offers to build the road at a lower cost wins regardless of quality, under two alternative institutional arrangements. The first is regulation. In our basic model, we define regulation to mean that the PE is not allowed to exclude buyers from the auction. The alternative is discretion, which in our model is the absence of regulation. If the PE has discretion, she may exclude either bidder because of allegedly low 
quality. Quality levels are known to both bidders and the PE, perhaps from experience, but they are not legally verifiable. Discretion to exclude cannot then in practice be made contingent on bidder quality. We later also examine a model of regulation of transparency, i.e., whether the PE informs the outsider about the auction. Transparency is different from exclusion in that in practice there can be either more or less transparency than is legally required.

The upside of discretion is that PE may exclude a lower quality bidder who would otherwise win the auction by bidding less. The downside of discretion is that the PE may exclude the Outsider and make a corrupt deal with the Insider. We analyze the relationship between regulations and the overall quality of public institutions, captured by $\alpha$. When we turn to the empirical predictions of the model, we measure $\alpha$ across countries as higher overall government efficiency or as higher levels of human capital.

Regulation in this model is meant to capture the legal rules described in Section II, particularly the ease of exclusion. We assume that this rule binds, so the model cannot explain why in some countries, exclusion is restricted by law but common in practice. Discretion can lead to a divergence between rules and practice. Discretionary power is given to exclude low quality bidders, but can be used to exclude Outsiders. When the PE chooses to exclude a higher quality bidder, we can point to a divergence between rules and practice.

The model delivers a version of all three outcomes: corruption, Process, and Product. Corruption results from the PE making deals with the Insider. Bad Process (favoritism and absence of competition in the data) is unduly favoring the Insider by excluding the Outsider. Process may be poor even if the excluded Outsider delivers lower quality, because the benefits from including him may exceed the higher prices in a one-bidder auction. Product is captured by final quality and price, which in the data are measured as low quality and cost overruns. Poor Product manifests itself if the PE selects the Insider with poor quality. Product is equivalent to consumer welfare in the model, defined as quality minus price.

We assume that there is a maximum possible payment for the service $C_{\max }$, and that $\min \left[Q_{I}, Q_{O}\right]>C_{\max }>\max \left[K_{I}, K_{O}\right]$, so that it is always optimal to build and that both builders are willing to build for a fee of $C_{\max }$. All parameters are common knowledge. 
In a regulated second price auction with no exclusion, both bidders accurately report their bids and neither has a reason to bribe the PE. They do not benefit from knowing the bid of the other firm, and the PE cannot exclude either bidder. Since rules are obeyed, this model automatically delivers the result that regulation reduces corruption. The regulated second price auction does not, however, maximize consumer surplus, both because it ignores quality and because the winning bidder usually earns profits.

When the PE has discretion, the Insider can bribe the PE either to keep him in the auction when he delivers low quality, or to exclude the Outsider. In negotiations over bribes, we assume that the PE has bargaining power $\beta$, so the Nash bargain maximizes: ( $U_{\text {BARGAIN }}-$ $\left.U_{N O}\right)^{\beta}\left(\pi_{B A R G A I N}-\pi_{N O}\right)^{1-\beta}$, where $U_{B A R G A I N}$ and $\pi_{B A R G A I N}$ are the PE's welfare and the Insider's profits in a bargain, and $U_{N O}$ and $\pi_{N O}$ are the PE's welfare and the Insider's profits if no bargain is reached. The bargain may involve a bribe from the Insider to the PE, but not from the $\mathrm{PE}$ to the Insider. We assume that a bribe of $\mathrm{B}$ costs the Insider $\theta B$, with $\theta>1$. The parameter $\theta$ captures the waste involved in bribes that do not involve direct cash transfers, such as quasi-legal gifts, campaign contributions, or favors. Stronger institutional environments have a higher value of both $\theta$ and $\alpha$. Empirically, we also identify higher values of national human capital with higher values of $\alpha$ and $\theta$.

At the negotiation stage, the PE can commit to exclude the Outsider or include the Insider in exchange for a bribe, but cannot threaten to take any action that is not in her ex post interest. If the bargaining fails, the PE optimizes her own welfare which with no bribe coincides with social welfare, defined as consumer surplus. Denote $\Delta=Q_{O}-Q_{I}$ the quality gap between outsiders and insiders. We then have (all proofs appear in Appendix B):

Proposition 1: If $K_{0}<K_{I}$, then discretion increases welfare by excluding the low quality Outsider if $\Delta<-\left(C_{\max }-K_{I}\right)$, decreases welfare by excluding the Outsider if $-\left(C_{\max }-K_{I}\right)<\Delta<$ $\left(\frac{1}{\alpha \theta}-1\right)\left(C_{\max }-K_{I}\right)$, and has no impact on welfare if $\Delta>\left(\frac{1}{\alpha \theta}-1\right)\left(C_{\max }-K_{I}\right)$.

If $K_{0}>K_{I}$, then discretion increases welfare by excluding the low quality insider if $\Delta>$ $\operatorname{Max}\left[C_{\max }-K_{O}+\frac{K_{O}-K_{I}}{\alpha \theta}, \frac{C_{\max }-K_{I}}{\alpha \theta}\right]$, decreases welfare by excluding the outsider if $\alpha \theta<1$ and $\Delta<\frac{C_{\max }-K_{I}}{\alpha \theta}$, and has no impact on welfare if $\alpha \theta>1$ and $\Delta<C_{\max }-K_{O}+\frac{K_{O}-K_{I}}{\alpha \theta}$. 
Figures 6 and 7 illustrate the different possibilities shown in Proposition 1. Figure 6 shows the case in which the Outsider has lower costs, and would win the auction if not excluded. The horizontal axis is $\alpha \theta$, which reflects the quality of government or the innate accountability of the PE. The vertical axis plots $\Delta$, the quality advantage of the Outsider.

Figure 6: Outsider as the Lower Cost Bidder

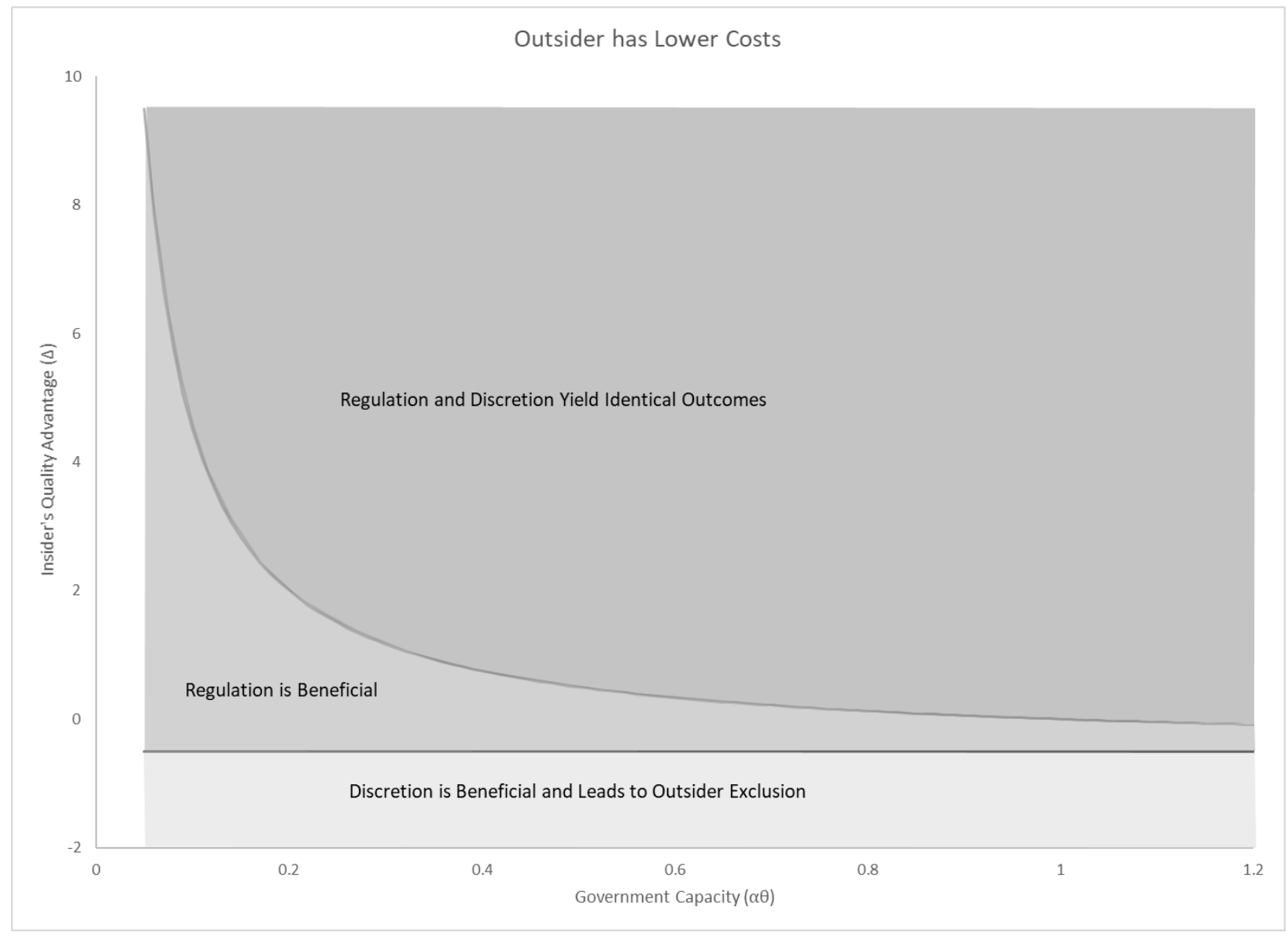

In the top region, where the quality advantage of the Outsider is high, discretion delivers the same welfare as regulation. In this region, the PE always includes such a high quality Outsider in the auction, even though the Insider offers bribes to exclude him. The region becomes smaller when $\alpha \theta$ is low, and it disappears entirely when $\alpha \theta$ equals zero.

In the middle region, discretion leads the PE to exclude the Outsider, which is a bad outcome. The price always rises. Quality also falls if $\Delta>0$. In this region, if $\alpha \theta<1$ and $\Delta>0$, discretion creates a divergence between law and practice: the PE is meant to exclude low quality 
bidders, but in practice excludes the higher quality Outsider in exchange for a bribe. If $\alpha \theta>1$, then the PE only excludes the Outsider with lower quality than the Insider, so law and practice are aligned. Yet that exclusion may still be socially suboptimal if $\Delta>-\left(C_{\max }-K_{I}\right)$, because the gain in quality does not offset the higher price that must be paid in a less competitive auction.

In the bottom region, where $\Delta<-\left(C_{\max }-K_{I}\right)$, discretion also leads the PE to exclude the Outsider, but the Outsider's quality is so low that this outcome is socially optimal. Practices align with laws. Moreover, there are no bribes because the PE cannot commit to leave the Outsider in the auction, and therefore cannot extract any rents. If we had a distribution of values of $\Delta$, then at low levels of $\alpha \theta$ efficient exclusion would be rare relative to the inefficient exclusion of higher quality Outsiders. For higher levels of $\alpha \theta$, efficient exclusion becomes the norm so that practices and laws are more aligned.

Figure 7 shows the case where the Insider is the lower cost bidder $\left(K_{0}<K_{I}\right)$.

Figure 7: Insider as the Lower Cost Bidder

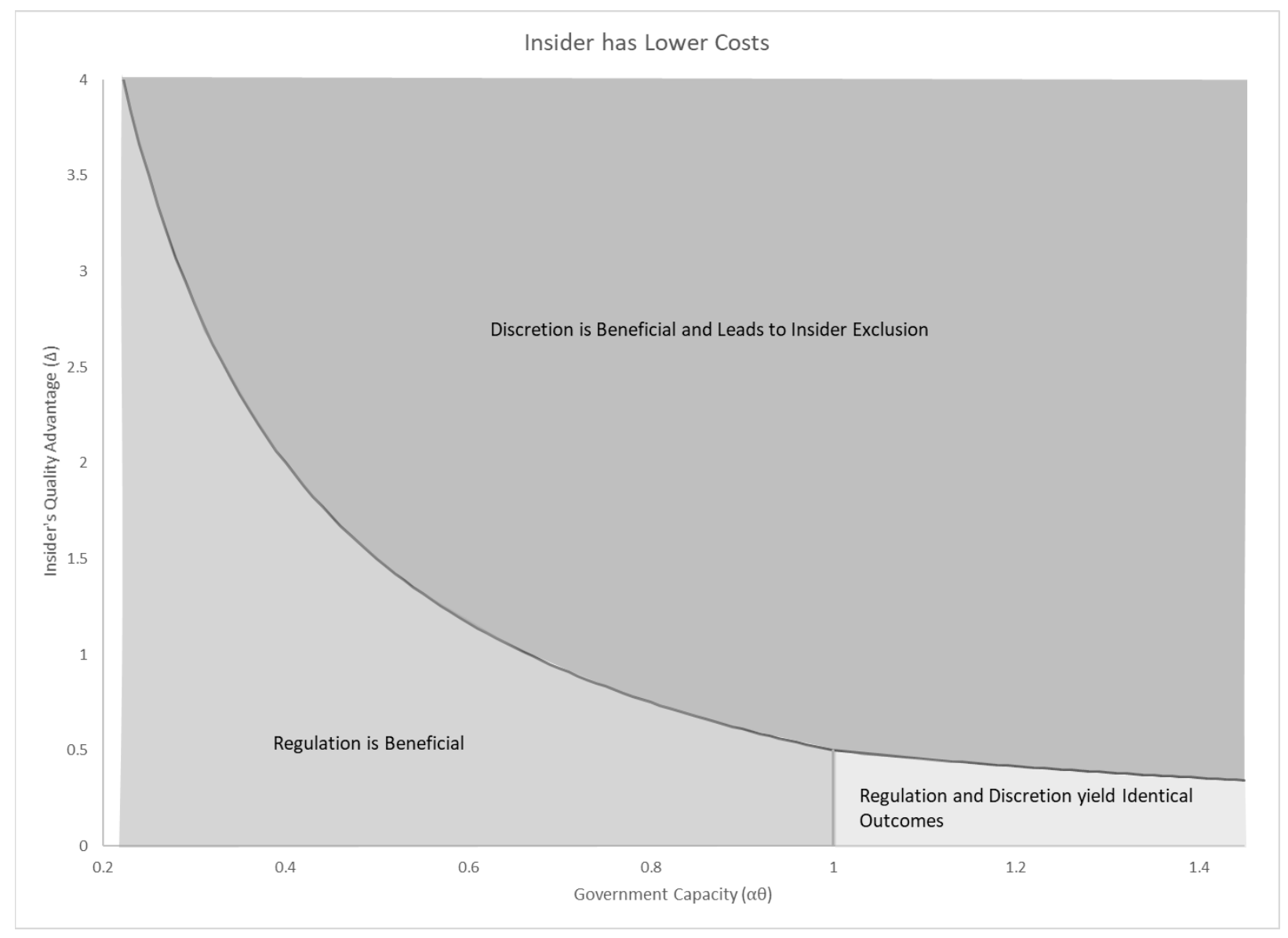


In this case, there are also three regions. When $\Delta$ is above the downward sloping curve, discretion leads to better outcomes because the low-quality Insider is excluded from the auction. In this region, there are no bribes and laws and practices are aligned. Once again, as $\alpha \theta$ falls, this region becomes smaller and as $\alpha \theta$ goes to zero, it disappears.

When $\alpha \theta<1$ and $\Delta$ is below the downward sloping curve, discretion leads to bad outcomes because the Outsider is excluded. This region features the mismatch between laws and practice that the model predicts would appear in weak governance regimes. The PE is supposed to exclude low quality bidders, but instead excludes high quality outsiders in exchange for bribes. In this region, bribes do not change the identity of the winner relative to the regulated second price auction - the Insider wins in either case — but they raise the price. The PE uses discretion to favor the Insider and creates a non-competitive auction, which we measure as inferior Process. Product (and consumer welfare) also decline because discretion leads to a higher price for the same road.

When $\alpha \theta>1$ and $\Delta$ is below the downward sloping curve, discretion is irrelevant. An accountable PE does not exclude the Outsider when the Outsider's quality advantage is modest, and so the regulated second price auction is replicated even with discretion. ${ }^{5}$ With strong enough institutions, practices and laws are aligned, since discretion is used only to exclude the low quality Insider, and not to exclude the Outsider in order to increase Insider profits.

\section{Regulation with Endogenous Quality}

The case for discretion, as opposed to regulation, becomes stronger when firms know the rules and can respond by changing quality or cost or both. Discretion enables PEs to guard against opportunism because regulation makes them a fixed target for optimizing bidders. ${ }^{6}$ We follow Hart, Shleifer and Vishny (1997) and assume that the Insider, but not the Outsider, can take an

\footnotetext{
${ }^{5}$ Discretion produces the same consumer welfare in this region, but for a small parameter range it transfers wealth from the insider to the PE. The Insider bribes the PE to keep him in the auction, despite low quality. In this case laws and practice diverge slightly, but Product does not get worse relative to the regulated outcome.

${ }^{6}$ This is very closely related to the idea of judicial discretion and common law, where judges are often allowed to use broad principles such as fiduciary duty to adjudicate disputes. In civil law judges rely on more precise legal rules, which opens opportunities for manipulation (see La Porta et al. 1998, 2008).
} 
action that reduces both costs and quality, e.g. by using inferior materials. This action is taken before any bidding or negotiation and requires an effort of $\varepsilon$, which is arbitrarily small. This effort is only used in the model to break ties, and is subsequently treated as a minute fixed cost.

The Outsider's quality and costs remain at $Q_{O}$ and $K_{O}$. If the Insider does not invest $\varepsilon$, we assume his quality is also $Q_{O}$ and his costs are $K_{O}+A$. If the insider invests $\varepsilon$, his quality falls to $Q_{O}-\Delta$ and costs fall to $K_{O}-A$. We assume that $\Delta>C_{\max }-K_{O}+A$, so it is optimal to exclude the Insider who has cut costs and quality from the auction. In a second price auction, quality choice generates a race to the bottom, since the insider cuts costs to win the auction. Consumer welfare then equals $Q_{O}-\Delta-K_{O}$. Proposition 2 details outcomes when the PE has discretion and can reject a bidder with low quality.

Proposition 2: If the PE has discretion, then (i) if $\alpha \theta>1$, the Insider does not cut quality, loses the auction, and consumer welfare is $Q_{O}-K_{O}-A$, (ii) if $1>\alpha \theta>\frac{C_{\max }-K_{O}+A}{\Delta}$, the Insider does not cut quality, the Outsider is excluded, the Insider wins the auction, and consumer welfare is $Q_{O}-C_{\max }$, and (iii) if $\alpha \theta<\frac{C_{\max }-K_{O}+A}{\Delta}$, the Insider cuts quality, the Outsider is excluded, the Insider wins the auction, and consumer welfare is $Q_{O}-\Delta-C_{\max }$.

The gains from discretion are highest when $\alpha \theta>1$ because, in that case, the threat of exclusion stops the Insider from cutting quality. The auction remains competitive and delivers a high quality product. When $1>\alpha \theta>\frac{C_{\max }-K_{O}+A}{\Delta}$, the Insider still does not cut quality but the Outsider is excluded from the auction. Discretion leads to higher quality but also higher prices. Because $\Delta>C_{\max }-K_{O}+A$, the gain in quality is higher than the loss in price. In this region, the PE cares enough about social welfare, so that bargaining induces the Insider to internalize the social welfare losses that come from cutting quality.

If $\alpha \theta<\frac{C_{\max }-K_{O}+A}{\Delta}$, discretion leads to a corrupt bargain between the Insider and the PE. The PE cares too little about social welfare to forgo bribes to get higher quality, so the Insider cuts quality. The quality delivered is the same as in the regulated second price auction, but discretion enables the PE to cut the Outsider from the bidding and push the price up. Discretion raises consumer welfare when government effectiveness is high, but reduces it when it is low. 
Rules, Practice and Transparency

In the preceding model, the divergence between laws and practice occurred when the PE was allowed to exclude a bidder, allegedly for low quality, but instead excluded high quality bidders in exchange for bribes. When the law prevents any exclusion, the PE is bound to follow that law. The PE could then have worse but not better practice than laws. In a different area of regulation, such as transparency, practice can easily exceed legal mandates. The law may not require transparency, but the PE may still choose it. Figure 8 shows the relationship between transparency law and in practice in our data. Many countries, such as Egypt and Algeria, have transparency practices weaker than laws. Other countries, such as the Netherlands, Lithuania and the Czech Republic, have transparency practices stronger than what laws require. By allowing the PE to make a transparency choice, we allow both positive and negative divergence between law and practice.

Figure 8: Transparency in Law and Practice

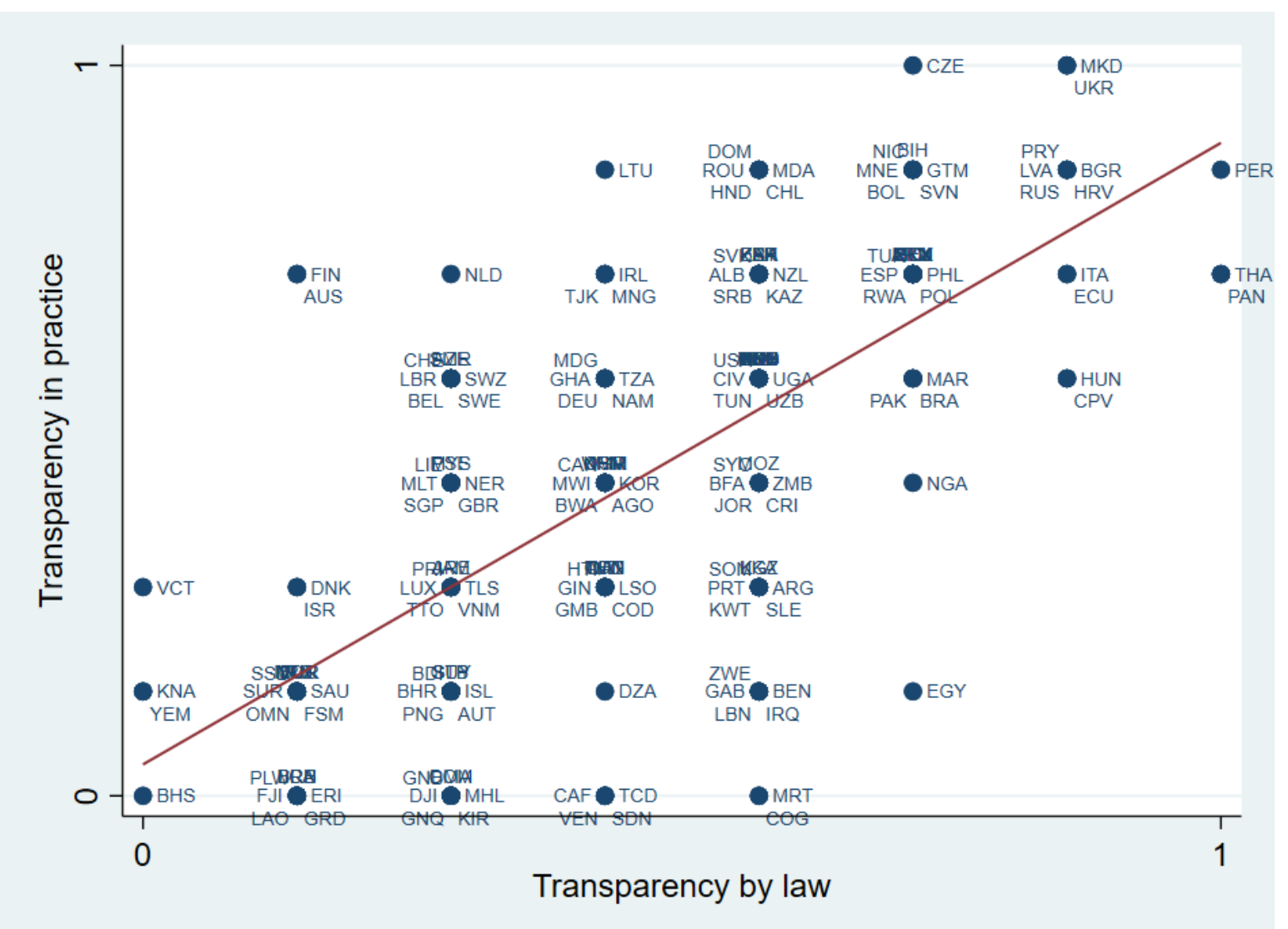


We now assume that $Q_{O}=Q_{I}$, so there is no legitimate case for exclusion, and that $K_{O}<$ $K_{I}$ so that the Insider loses the auction if the Outsider bids. Moreover, we assume that the Outsider cannot be excluded, but cannot bid when he does not know about the auction. We consider two institutional regimes. Transparency regulation means that the procuring entity is required to notify both bidders about the auction. Transparency discretion means that the procuring entity can freely choose whether to notify the Outsider.

We formalize transparency as the probability, denoted by $\pi$, that the Outsider learns about the auction. The value of $\pi$ is set by the PE and can be either $\pi_{L}<1$ or 1 . Absent a transparency law, the PE can set $\pi$ to either $\pi_{L}$ (which can be zero) or 1 at no cost. If transparency is regulated, the PE can either set $\pi=1$ or pay a cost $\alpha z>1$ to set $\pi=\pi_{L}$. The cost " $\alpha z$ " captures the hassle of deviating from legal norms and the risk of detection and penalty. This cost scales up with $\alpha$ so that cheating is costlier under more accountable governments. The PE negotiates with the Insider before choosing $\pi$. The PE can make a binding commitment to a level of transparency, or more accurately non-transparency. Both the Insider and the PE are risk neutral. Proposition 3 describes the interplay between transparency law and practice.

Proposition 3: If transparency is not regulated, the PE sets $\pi=1$ if $\alpha \theta>1$ and $\pi=\pi_{L}$ if $\alpha \theta<$ 1. If transparency is regulated, the PE sets $\pi=1$ if $\alpha \theta>\frac{C_{\max }-K_{I}}{C_{\max }-K_{I}+z}$ and $\pi=\pi_{L}$ if $\alpha \theta<$ $\frac{C_{\max }-K_{I}}{C_{\max }-K_{I}+Z}$.

Proposition 3 illustrates how laws are unnecessary when government effectiveness is high. If $\alpha \theta>1$, the PE ensures full transparency even without a transparency regulation. If effectiveness is low enough that $\alpha \theta<\frac{C_{\max }-K_{I}}{C_{\max }-K_{I}+z}$, then transparency is low even with transparency regulation. In that case, the Insider bribes the PE with or without regulation. Regulation only binds if $1>\alpha \theta>\frac{C_{\max }-K_{I}}{C_{\max }-K_{I}+z}$, for in that case, there is full transparency with regulation and limited transparency without regulation. In that region, regulation reduces bribes. The proposition 
implies that practices are better than the law stipulates in accountable governments and worse than legal mandates in unaccountable ones.

\section{Empirical Predictions of the Model}

We next turn to the empirical predictions of the model for the relationships between laws, practice, and outcomes, including corruption, Process, and Product.

Prediction \# 1: Procurement Laws deter corruption, especially in low capacity governments.

The model of the regulation of exclusion predicts no bribes when exclusion is regulated (forbidden), because the PE has no discretion to increase her profits. When the PE has discretion, the Insider can bribe her to exclude the Outsider. The model thus predicts that procurement regulation deters corruption. In contrast, the regulation of transparency does not entirely eliminate bribes. Since we allow the PE to flout the law at a cost, bribery still occurs in very low public

capacity countries. Even in settings with modest public capacity $\left(1>\alpha \theta>\frac{C_{\max }-K_{I}}{C_{\max }-K_{I}+z}\right)$, regulation eliminates bribes.

With both forms of regulation, bribes essentially disappear if government capacity $(\alpha \theta)$ is sufficiently high. If corruption is costly, or if the PE is publicly minded enough, she does not take bribes even if she has full discretion. The model then predicts that regulation should have a stronger negative impact on corruption at low levels of government capacity and human capital. Regulation of the public sector does not, however, increase corruption at any level of public capacity, which contrasts with the theory of regulation of private sector activity.

Prediction \# 2: Practices are better than laws in well governed countries and worse than laws in poorly governed countries.

When exclusion is not regulated, its practice is worse than the laws in low public capacity settings. When government capacity $(\alpha \theta)$ is sufficiently low, discretion to exclude bidders results in the exclusion of high quality bidders, since the low quality bidder pays a bribe. When exclusion is regulated, practices cannot be worse than laws because the laws are followed (by assumption). 
If we allowed the PE to pay a cost and avoid the regulation, as we do with transparency, we would also find that practices are worse than laws when exclusion is regulated.

For regulation of transparency, high public capacity leads to high transparency even without mandates. A high $\alpha \theta$ encourages the PE to notify the Outsider even without the rules, because competition serves the PE's objectives of lower cost and higher quality. Breaking the transparency rule by the PE is more common when government capacity is low. The model thus predicts that practice is better than laws when bureaucratic incentives are aligned with public welfare and worse than laws when these incentives are weak.

Prediction \# 3: Better governance improves Process and Product, regardless of laws.

In the model, higher $\alpha$ and $\theta$ lead to better Process and Product whenever the PE had any room to act. When the PE cannot exclude, these variables are irrelevant, since outcomes are everywhere the same. When the PE has discretionary power to exclude, good outcomes, such as the exclusion of low quality bidders, occur when $\alpha$ and $\theta$ are high and bad outcomes, such as the arbitrary exclusion of outsiders, occur when $\alpha$ and $\theta$ are low.

In the model of transparency, because the law can be avoided at a cost, the importance of public capacity is particularly clear. When the PE has control over transparency, high levels of $\alpha$ and $\theta$ lead to competitive auctions and lower prices, with or without a law. When $\alpha$ and $\theta$ are low, transparency is low, even with the law, so competition is lower and prices are higher.

Implication \#4: Laws improve Product and Process in poorly-governed countries and adversely affect them in well-governed countries.

In Section III, we showed that stricter laws correlate with better practice, better practice correlates with better Process and Product, but laws do not correlate positively with better Process and Product. The exclusion model suggests a clear and testable reason for this finding. Regulation is beneficial when $\alpha$ and $\theta$ are low because discretion leads to corruption. Regulation is harmful 
when $\alpha$ and $\theta$ are high because discretion enables the elimination of low-quality bidders. We see this prediction as the most important result of the model.

\section{Corruption, Laws, and Practice}

In this section, we empirically test the first two predictions: (1) regulations reduce corruption, and (2) practice falls short of rules in low public capacity countries and is better than rules in high capacity ones. We use two measures of public sector capacity: human capital and government effectiveness. The World Bank’s Human Capital Index (Angrist et al, 2019) runs from 0.293 to 0.884 with a standard deviation of 0.15 ; its correlation with the logGDP is 0.88 . The World Bank's Government Effectiveness Index runs from -2.47 to 2.21 with a standard deviation of 0.98 . Its correlation with the logGDP is 0.86 . Government effectiveness is close to the parameters of the model, but may also reflect procurement outcomes we use as dependent variables. The link between human capital and public capacity is less than perfect, but human capital is surely not

directly measuring the ability to handle procurement. Previous work (Glaeser, Ponzetto and Shleifer 2007, Pande 2011, Barro 2013) argues that national human capital captures the ability to discipline and staff governments.

\section{Does Regulation Reduce Corruption?}

In our model, the regulation of government constrains bureaucratic discretion and therefore the ability to engage corrupt contractors. The model predicts that rules reduce bribes. However, some research shows that regulation causes corruption, either because businesses pay bribes to capture their regulators (Stigler 1971) or because government officials introduce regulations to extract bribes (Djankov et al. 2003). In our study, in contrast, most of the regulations constrain government, not the contractors, although some of them may in principle encourage corruption.

The correlation between our corruption measure and the Laws index is -0.115 , though it is not statistically significant (Table 7, first column). In Table 9, we test whether this relationship holds if we control for government capacity, and whether it is weaker in higher capacity countries. The evidence demonstrates three findings. First, government capacity, measured either by human 
capital or government effectiveness, has a large and statistically significant effect on corruption. Second, controlling for government capacity, stricter procurement laws are strongly associated with less corruption. Third, we test the prediction of our model that when governance is sufficiently good, the impact of laws on corruption is attenuated. Laws always (weakly) reduce corruption. The third regression estimates the original specification above the median educated sample countries and the fourth for the below-median educated countries. For educated countries, the coefficient in laws is -0.12 , and statistically significant at the 5 percent level. For uneducated ones, the estimated coefficient is -0.06 , and statistically significant at the 10 percent level.

Table 9: Controlling for Government Capacity

\begin{tabular}{|l|c|c|c|c|}
\hline & \multicolumn{4}{|c|}{ Corruption as a Function of Regulation and Government Capacity } \\
\hline & OLS & OLS & More Educated & Less Educated \\
\hline \multirow{2}{*}{ Law Index } & $-0.086^{* * *}$ & $-0.093^{* * *}$ & $-0.127^{* *}$ & $-0.062^{*}$ \\
& $(0.028)$ & $(0.028)$ & $(0.050)$ & $(0.033)$ \\
\hline \multirow{2}{*}{ Human Capital } & $-1.429^{* * *}$ & $-1.016^{* * *}$ & $-1.518^{* * *}$ & $-1.540^{* * *}$ \\
& $(0.112)$ & $(0.224)$ & $(0.366)$ & $(0.263)$ \\
\hline Government & & $-0.075^{* *}$ & & \\
Efficiency & & $(0.035)$ & .23 & .32 \\
\hline $\mathrm{R}^{2}$ & .52 & .54 & 77 & 77 \\
\hline $\mathrm{N}$ & 154 & 154 & & \\
\hline
\end{tabular}

\section{Laws and Practice in High and Low Human Capital Countries}

The model predicts that practice is stricter than laws in well-governed countries and falls short in poorly governed ones. To test this prediction we compare practice and laws overall and for the four categories. We conduct three tests. Is practice stricter than laws in high human capital countries? Is practice looser than laws in low human capital ones? Is the gap between practice and laws higher in high than in low human capital countries? The first two tests apply if laws and practice refer to exactly the same thing. The third test is more appropriate under a mismatch.

Table 10 splits the sample at the median education level and compares the mean levels of laws and practice across countries. The first row shows results for overall laws and practice. The mean laws index in low human capital countries is 2.009 and the mean practice index is 1.666. The difference is highly statistically significant, with a t-statistic of 4.573. The mean laws index in high human capital countries is 1.941 and the mean practice index is 2.341. Again, the difference 
is statistically significant, with a t-statistic of -4.273 . The last column tests whether the difference between laws and practice is significantly higher in countries with human capital levels above the median. Unsurprisingly, the difference is higher, with t-statistic of -6.203. Results are very similar if we sort on government effectiveness rather than human capital.

Table 10: Laws and Practice in Countries with different levels of Education

\begin{tabular}{|c|c|c|c|c|c|c|c|}
\hline Variable Means & \multicolumn{3}{|c|}{ Below Median Human Capital } & \multicolumn{3}{|c|}{ Above Median Human Capital } & \multirow{2}{*}{$\begin{array}{l}\text { Probability } \\
\text { (Practice- } \\
\text { Laws) is } \\
\text { Higher in } \\
\text { Low H.C. } \\
\text { Countries }\end{array}$} \\
\hline & Laws & Practice & $\begin{aligned} & \text { Prob. } \\
& \text { Laws } \\
&= \text { Practice } \\
&\text { ( } \mathrm{T}-\text { Stat })\end{aligned}$ & Laws & Practice & $\begin{aligned} & \text { Prob. } \\
& \text { Laws } \\
&=\text { Practice } \\
& \text { (T -Stat) }\end{aligned}$ & \\
\hline Overall Index & $\begin{array}{c}2.009 \\
(0.063) \\
\end{array}$ & $\begin{array}{c}1.666 \\
(0.065) \\
\end{array}$ & $\begin{array}{c}0.000 \\
(4.573)\end{array}$ & $\begin{array}{c}1.941 \\
(0.075) \\
\end{array}$ & $\begin{array}{c}2.341 \\
(0.067) \\
\end{array}$ & $\begin{array}{c}0.000 \\
-4.273 \\
\end{array}$ & $\begin{array}{c}0.000 \\
-6.203 \\
\end{array}$ \\
\hline Transparency & $\begin{array}{c}0.493 \\
(0.021) \\
\end{array}$ & $\begin{array}{c}0.414 \\
(0.029)\end{array}$ & $\begin{array}{c}0.001 \\
(3.343) \\
\end{array}$ & $\begin{array}{c}0.510 \\
(0.026)\end{array}$ & $\begin{array}{c}0.562 \\
(0.027)\end{array}$ & $\begin{array}{c}0.019 \\
-2.387\end{array}$ & $\begin{array}{c}0.000 \\
-4.073\end{array}$ \\
\hline Competition & $\begin{array}{c}0.592 \\
(0.022)\end{array}$ & $\begin{array}{c}0.506 \\
(0.027)\end{array}$ & $\begin{array}{c}0.004 \\
(2.950)\end{array}$ & $\begin{array}{c}0.535 \\
(0.025)\end{array}$ & $\begin{array}{c}0.636 \\
(0.028)\end{array}$ & $\begin{array}{c}0.000 \\
-3.942\end{array}$ & $\begin{array}{c}0.000 \\
-4.821\end{array}$ \\
\hline $\begin{array}{l}\text { Limits to } \\
\text { Exclusion }\end{array}$ & $\begin{array}{c}0.267 \\
(0.022) \\
\end{array}$ & $\begin{array}{c}0.474 \\
(0.031) \\
\end{array}$ & $\begin{array}{c}0.000 \\
(-5.856) \\
\end{array}$ & $\begin{array}{c}0.301 \\
(0.021)\end{array}$ & $\begin{array}{c}0.673 \\
(0.033) \\
\end{array}$ & $\begin{array}{r}0.000 \\
-8.995 \\
\end{array}$ & $\begin{array}{c}0.002 \\
-3.011 \\
\end{array}$ \\
\hline $\begin{array}{l}\text { Integrity of } \\
\text { Contract }\end{array}$ & $\begin{array}{c}0.658 \\
(0.031) \\
\end{array}$ & $\begin{array}{c}0.271 \\
(0.018) \\
\end{array}$ & $\begin{array}{c}0.000 \\
(11.537)\end{array}$ & $\begin{array}{c}0.595 \\
(0.029) \\
\end{array}$ & $\begin{array}{c}0.470 \\
(0.025) \\
\end{array}$ & $\begin{array}{l}0.003 \\
3.036 \\
\end{array}$ & $\begin{array}{c}0.000 \\
-4.913 \\
\end{array}$ \\
\hline $\mathrm{N}$ & 78 & 78 & 78 & 77 & 77 & 77 & 155 \\
\hline
\end{tabular}

Note: Standard errors are in parentheses.

The pattern in the data is clear. Practice is good in well governed and well-educated countries and laws are less restrictive. Practice is weak in poorly governed and educated countries and laws are more restrictive. These findings echo the result in the transparency model that, with high government capacity, practice is strong and laws are unnecessary, whereas with low capacity, practice is weak even if laws are on the books.

The rest of Table 10 shows the results for the four distinct elements of laws and practice. In worse educated countries, laws are stricter than practice for transparency, competition, and integrity of contract (though not for limits of exclusion). In better educated countries, laws are less binding than practice for transparency, competition, and exclusion, though not for the integrity of contract. Some of this may be the consequence of practice not exactly mirroring laws. But in our ultimate test of laws vs practice in educated vs uneducated countries, we find the same result for every sub-index as we do for the overall index of laws. 
In summary, laws are not the same as practice, and mandating a procurement policy does not mean that it will be put into practice. Laws do predict practice, but governmental capacity does as well. In better educated and well governed countries, procuring entities follow good practice even without legal requirements. In poorly educated and misgoverned countries, procuring entities have worse practice, despite extensive laws meant to govern procurement.

\section{Laws and Outcomes in Rich and Poor Countries}

In this final empirical section, we establish two key facts. First, we show that procurement-specific rules are less important than the overall quality of government or national human capital for procurement outcomes. Well educated countries with capable governments achieve good procurement outcomes no matter what rules they have on the books. Second, we find support for the central implication of the model that rules are helpful when governance quality is low and harmful when it is high. If bureaucrats are accountable, rules that restrict their discretion do more harm than good. When bureaucrats are not accountable, rules limit their misconduct.

These findings resolve the conundrum identified in Section III that although laws predict practice and practice predicts outcomes, laws do not predict outcomes. The answer is that laws are positively correlated with outcomes in low human capital countries and negatively in high human capital ones. Across the full sample, the heterogeneous impact of rules makes them seem irrelevant. In fact, we see that laws do matter, but they help in some circumstances and harm in others. This is a central prediction of our model, and we confirm it empirically here.

As a preliminary step, Table 11 shows the correlations between human capital and government effectiveness and our two procurement outcomes. The table parallels earlier findings

in Table 6, except here we control for public capacity. In these regressions, laws are never statistically significant in predicting outcomes, whereas public capacity is consistently significant, with explanatory power of $30-40 \%$. These results frame our puzzle that laws in the full sample do not seem to matter. 
Table 11: Process, Product, and the Quality of Government

\begin{tabular}{|c|c|c|c|c|c|c|}
\hline & $\begin{array}{c}\text { Efficiency of } \\
\text { Process }\end{array}$ & $\begin{array}{c}\text { Efficiency of } \\
\text { Process }\end{array}$ & $\begin{array}{c}\text { Efficiency of } \\
\text { Process }\end{array}$ & $\begin{array}{c}\text { Quality of } \\
\text { Product }\end{array}$ & $\begin{array}{c}\text { Quality of } \\
\text { Product }\end{array}$ & $\begin{array}{c}\text { Quality of } \\
\text { Product }\end{array}$ \\
\hline Laws & $\begin{array}{c}0.031 \\
(0.293)\end{array}$ & $\begin{array}{c}-0.083 \\
(0.240)\end{array}$ & $\begin{array}{c}0.162 \\
(0.285)\end{array}$ & $\begin{array}{c}0.004 \\
(0.229)\end{array}$ & $\begin{array}{c}0.094 \\
(0.190)\end{array}$ & $\begin{array}{c}0.120 \\
(0.220)\end{array}$ \\
\hline $\begin{array}{l}\text { Human } \\
\text { Capital }\end{array}$ & $\begin{array}{c}8.425^{* * *} \\
(1.175)\end{array}$ & & $\begin{array}{c}1.204 \\
(2.297) \\
\end{array}$ & $\begin{array}{c}9.275^{* * *} \\
(0.918)\end{array}$ & & $\begin{array}{c}2.892 \\
(1.774)\end{array}$ \\
\hline $\begin{array}{l}\text { Gov. } \\
\text { Efficiency }\end{array}$ & & $\begin{array}{c}1.399 * * * \\
(0.161)\end{array}$ & $\begin{array}{c}1.306 * * * \\
(0.362)\end{array}$ & & $\begin{array}{c}1.505^{* * *} \\
(0.128)\end{array}$ & $\begin{array}{c}1.155^{* * * *} \\
(0.279)\end{array}$ \\
\hline $\mathrm{R}^{2}$ & 0.255 & 0.298 & 0.314 & 0.406 & 0.433 & 0.466 \\
\hline $\mathrm{N}$ & 155 & 186 & 155 & 155 & 186 & 155 \\
\hline
\end{tabular}

But what if we distinguish between rich and poor countries? The model predicts that restricting the PE's discretion is efficiency-promoting in countries with poor government capacity and harmful in countries with high capacity. When the Product index is regressed on laws in the high human capital subsample, we estimate:

$$
\text { Product }=\frac{-1.01}{(0.35)} \cdot \text { Laws }+\begin{aligned}
& 3.06 \\
& (.72)
\end{aligned}
$$

The r-squared is 0.10 . When we run the same regression in the low human capital subsample, we estimate:

$$
\text { Product }=\begin{gathered}
0.95 \\
(0.35)
\end{gathered} \cdot \text { Laws }-\begin{aligned}
& 2.92 \\
& (.73)
\end{aligned}
$$

The r-squared is 0.09. The relationships for high and low human capital countries are shown in Figures 9 and 10, respectively. The regressions are mirror images of each other. Procurement outcomes improve with the regulation of government in less educated countries and deteriorate in more educated countries. 
Figure 9: Law and Quality of Product in High Human Capital Countries

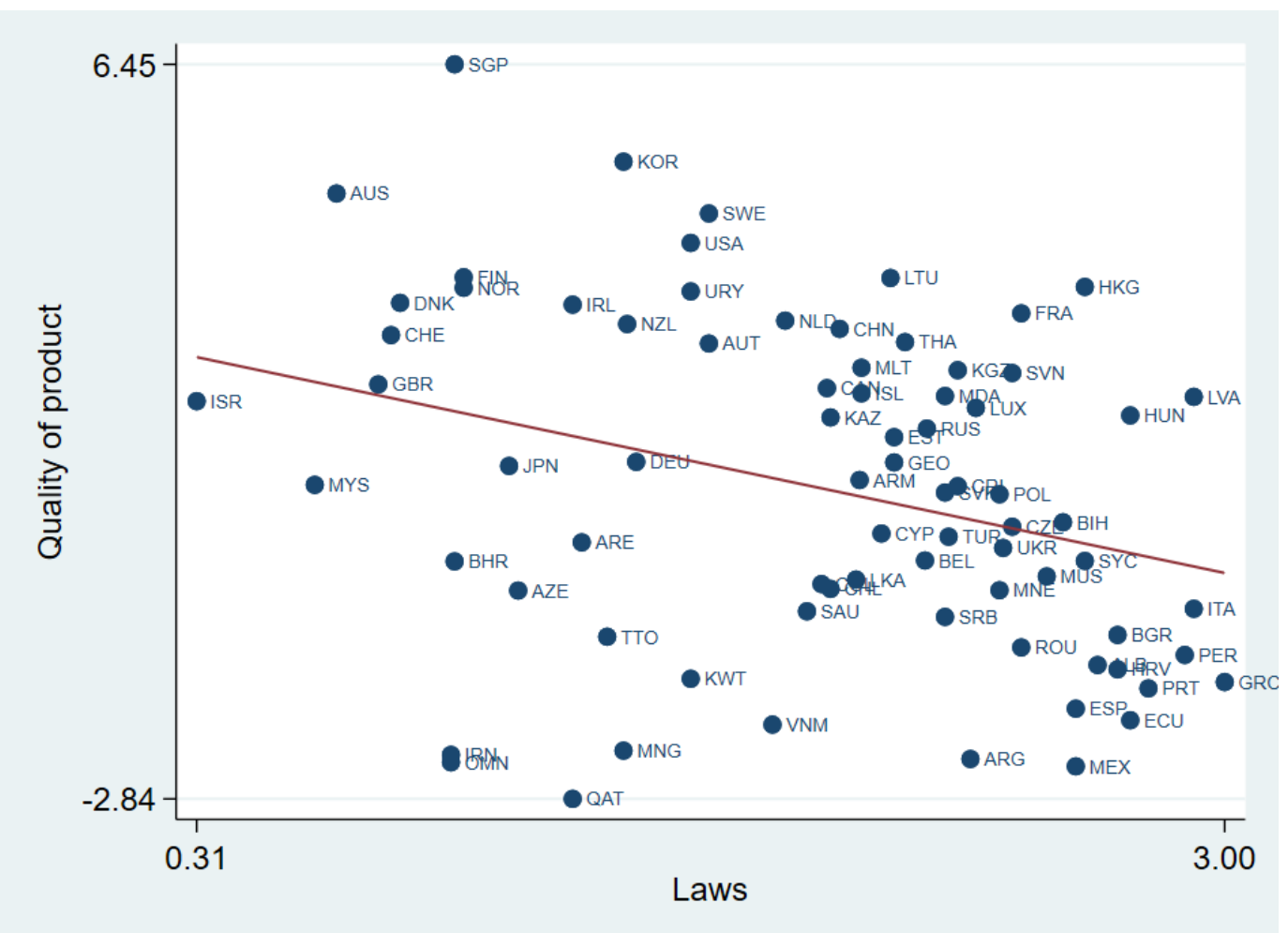

Figure 10: Law and Quality of Product in Low Human Capital Countries

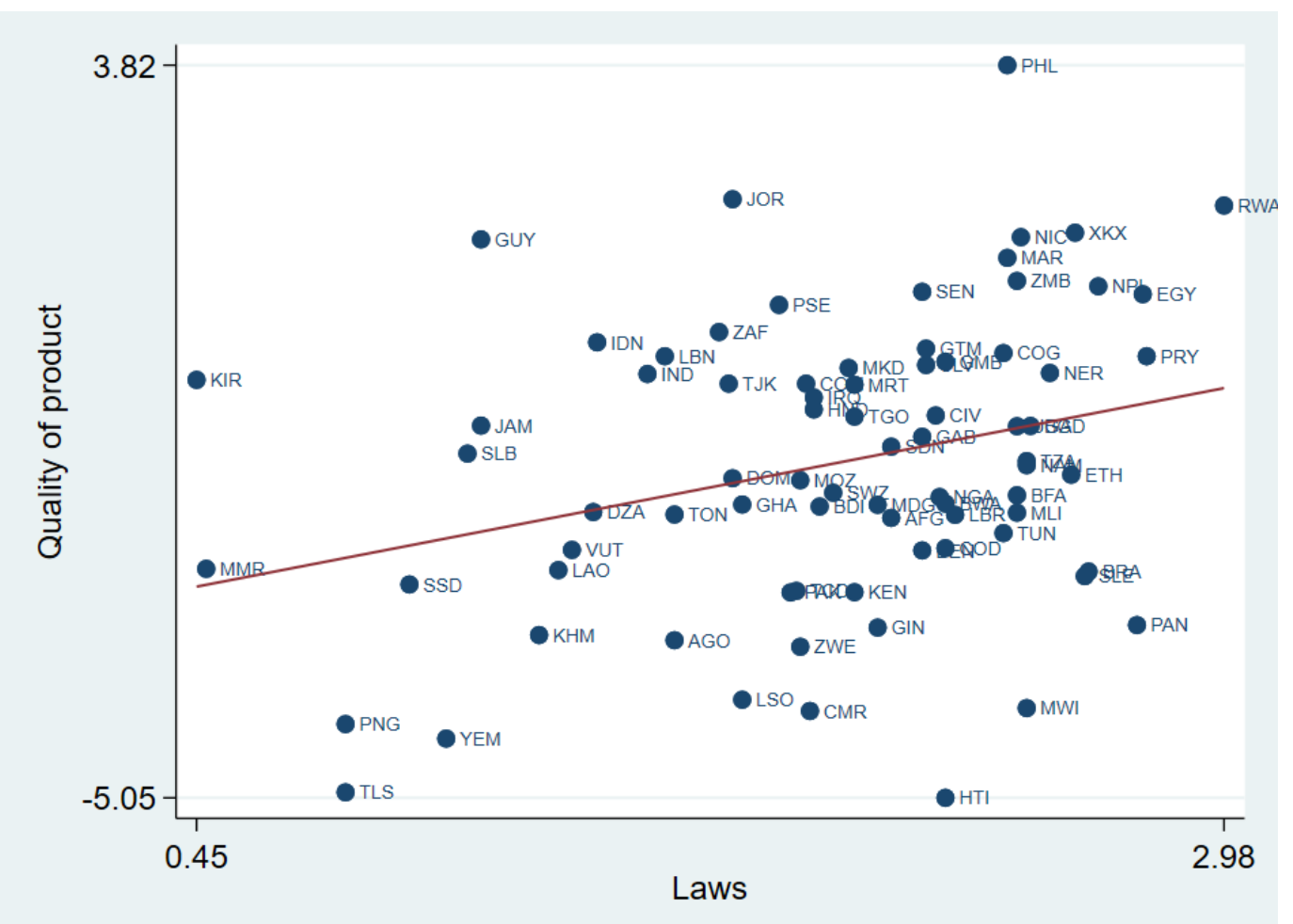


We next turn to the continuous interaction between the regulation index and the measures of government capacity in Table 12.

Table 12: Testing with Continuous Interactions

\begin{tabular}{|l|c|c|c|c|c|c|}
\hline & \multicolumn{3}{|c|}{ Process } & \multicolumn{3}{c|}{ Product } \\
\hline \multirow{2}{*}{ Laws } & 0.237 & 0.107 & 0.085 & 0.276 & 0.470 & 0.428 \\
& $(0.294)$ & $(0.362)$ & $(0.373)$ & $(0.216)$ & $(0.297)$ & $(0.310)$ \\
\hline \multirow{2}{*}{ Human Capital } & $8.692^{* * *}$ & 2.880 & 1.462 & $9.627^{* * *}$ & $6.550^{* * *}$ & $4.940^{* *}$ \\
& $(1.148)$ & $(2.580)$ & $(2.567)$ & $(0.846)$ & $(2.117)$ & $(2.131)$ \\
\hline Gov. & & $1.121^{*}$ & $1.324^{* *}$ & & $2.230^{* * *}$ & $2.458^{* * *}$ \\
Effectiveness & & $(0.642)$ & $(0.648)$ & & $(0.527)$ & $(0.538)$ \\
\hline Human & $-5.626^{* * *}$ & $-6.717^{* * *}$ & & $-7.414^{* * *}$ & $-7.649^{* * *}$ & \\
Capital*Law & $(1.859)$ & $(2.268)$ & & $(1.369)$ & $(1.861)$ & \\
\hline \multirow{2}{*}{ Gov. Eff.*Laws } & & & $-0.837^{* *}$ & & & $-0.921^{* * *}$ \\
& & & $(0.329)$ & & & $(0.273)$ \\
\hline \multirow{2}{*}{ Log(GDP) } & & -0.173 & -0.247 & & $-0.599^{* *}$ & $-0.686^{* * *}$ \\
& & $(0.297)$ & $(0.297)$ & & $(0.244)$ & $(0.247)$ \\
\hline Polity2 & & $0.103^{*}$ & 0.085 & & $0.073^{*}$ & 0.0516 \\
& & $(0.053)$ & $(0.054)$ & & $(0.044)$ & $(0.045)$ \\
\hline Function of & & 0.033 & 0.064 & & $-0.248 * *$ & $-0.212^{* *}$ \\
Government & & $(0.120)$ & $(0.120)$ & & $(0.098)$ & $(0.099)$ \\
\hline \multirow{2}{*}{ Efficiency (WEF) } & & -0.288 & -0.259 & & -0.196 & -0.159 \\
& & $(0.263)$ & $(0.264)$ & & $(0.216)$ & $(0.220)$ \\
\hline $\mathrm{R}^{2}$ & 0.298 & 0.466 & 0.456 & 0.502 & 0.583 & 0.565 \\
\hline $\mathrm{N}$ & 155 & 126 & 126 & 155 & 126 & 126 \\
\hline
\end{tabular}

Process is the dependent variable in the first three regressions of Table 12, and Product in the last three regressions. Regressions (1), (2), (4) and (5) interact human capital with laws. Regressions (3) and (6) interact government efficiency with laws. We demean both variables in the interaction, so that the reported coefficients on the main variable can be interpreted as their estimated effect at the mean level of the other variable. The analysis conveys several results. First, laws by themselves on average have no influence on either Process or Product. Second, either human capital or effectiveness generally has a positive effect on both Process and Product. Third, and most important, the interaction terms are all negative and statistically significant, which is a striking confirmation of our model's principal prediction. The effect of laws on Product and Process is much greater in poor than in rich countries. Procurement laws have beneficial effects in developing countries, but not in rich ones where government effectiveness sis high.

Table 13 examines the impact of these interaction terms on the six components of Product and Process (recall that the variables here are coded so that higher values mean worse outcomes). 
All interaction coefficients are positive. In the top panel, five of the regressions show interactions that are statistically significant and economically meaningful. The interaction is not significant for the no competition outcome.

Table 13: Testing with Interaction Terms

\begin{tabular}{|c|c|c|c|c|c|c|}
\hline & Collusion & Favoritism & $\begin{array}{c}\text { No } \\
\text { Competition }\end{array}$ & Time & Cost Overrun & Low Quality \\
\hline Laws & $-0.062^{* *}$ & 0.010 & -0.023 & $-0.060^{*}$ & -0.021 & -0.006 \\
& $(0.029)$ & $(0.031)$ & $(0.030)$ & $(0.036)$ & $(0.025)$ & $(0.028)$ \\
\hline Human & $-0.630^{* * *}$ & $-0.576^{* * *}$ & $-0.938^{* * *}$ & $-1.345^{* * *}$ & $-0.510^{* * *}$ & $-0.750^{* * *}$ \\
Capital & $(0.111)$ & $(0.116)$ & $(0.115)$ & $(0.139)$ & $(0.096)$ & $(0.105)$ \\
\hline Laws*Human & $0.626^{* * *}$ & $0.600^{* * *}$ & 0.183 & $0.704^{* * *}$ & $0.646^{* * *}$ & $0.541^{* * *}$ \\
Capital & $(0.182)$ & $(0.190)$ & $(0.189)$ & $(0.225)$ & $(0.155)$ & $(0.172)$ \\
\hline $\mathrm{R}^{2}$ & 0.215 & 0.192 & 0.307 & 0.397 & 0.222 & 0.285 \\
\hline $\mathrm{N}$ & 154 & 154 & 154 & 155 & 155 & 154 \\
\hline
\end{tabular}

\section{Conclusion}

Most countries regulate their bureaucracies in addition to regulating their private sectors. We investigate such regulation in the case of public procurement, using the hypothetical study of a road resurfacing contract, in 187 countries. We distinguish between regulatory rules, and regulatory practice, and measure them in terms of how much discretion they allow the procuring entities in selecting and managing subcontractors. We then evaluate the relationship between the two as well as their effect on procurement outcomes, such as corruption, the efficiency of procurement process, and the quality of the procurement product.

A preliminary look at the evidence shows tremendous dispersion on how heavily countries regulate the procurement process in law, with poorer countries generally using more extensive regulation. We find that procurement laws are highly, though not perfectly, correlated with procurement practice. However, we also find some puzzling evidence. Although better procurement practice is highly correlated with procurement outcomes, more extensive procurement laws, although they are associated with less corruption, generally do not predict better procurement outcomes. The question is why? 
We propose a new theoretical framework for addressing this question. The theory describes a procurement auction in which the organizers may take bribes in exchange for favoring connected bidders. The model allows us to discuss a variety of regulations of the procurement process, but also delivers a basic - and not entirely surprising -- prediction, namely that procurement regulation is more socially valuable when the incentives of the bureaucrats are further away from social welfare. Properly motivated bureaucrats require fewer rules.

We then bring the theoretical predictions to the cross-country data and find strong support. Heavier regulation of procurement is associated with better outcomes in countries with lower quality public sectors, and with worse outcomes in countries with higher quality ones. The evidence explains the puzzle that, overall, there is no relationship between procurement laws and outcomes - one needs to sort on government capacity in the analysis. The evidence is consistent with recent findings from better identified but more specific settings which point to the benefits of bureaucratic discretion (Coviello et al. 2018, Bandiera et al. 2020, Decarolis et al. 2020).

There is a broader point as well. In many settings, economists and legal scholars see laws and their enforcement as complements. Laws are more effective in countries with better judiciaries, bureaucracies, etc. Here we find the opposite: laws and enforcement capabilities are substitutes. Countries with weak bureaucracies need strict laws to regulate them; countries with strong bureaucracies can lay off a little. This message has application to the design of institutions, particularly the regulation of government. 


\section{References}

Angrist, Noam, Simeon Djankov, Pinelopi Goldberg, and Harry Patrinos. 2019. "Measuring Human Capital,” Available at SSRN: http://dx.doi.org/10.2139/ssrn.3339416.

Bandiera, Oriana, Andrea Prat, and Tommaso Valletti. 2009. "Active and Passive Waste in Government Spending: Evidence from a Policy Experiment,” The American Economic Review, 99(4): 1278-1308.

Bandiera, Oriana, Michael Carlos Best, Adnan Qadir Khan, and Andrea Prat. 2020. “The Allocation of Authority in Organizations: A Field Experiment with Bureaucrats,” London School of Economics, London, mimeo.

Banerjee Abhijit, Rema Hanna, and Sendhil Mullainathan. 2012. “Corruption,” Handbook of Organizational Economics, Elsevier.

Banfield, Edward. 1975. “Corruption as a Feature of Governmental Organization,” The Journal of Law and Economics, 18(3): 587-605.

Baranek, Bruno and Vitezslav Titl. 2020. “The Cost of Favoritism in Public Procurement," Princeton University, Princeton, New Jersey, mimeo.

Barro, Robert J. 1999. “Determinants of Democracy,” Journal of Political Economy, 107(S6): 158-183.

Barro, Robert J. 2013. “Education and Economic Growth,” Annals of Economics and Finance, Society for AEF, 14(2): 301-328.

Barro, Robert J. and Rachel M. McCleary. 2005. “Which Countries Have State Religions?” The Quarterly Journal of Economics, 120(4): 1331-1370.

Bertrand, Marianne, Simeon Djankov, Rema Hanna, and Sendhil Mullainathan. 2007. “Obtaining a Driver's License in India: An Experimental Approach to Studying Corruption,” The Quarterly Journal of Economics, 122(4): 1639-1676.

Best, Michael Carlos, Jonas Hjort, and David Szakonyi. 2019. "Individuals and Organizations as Sources of State Effectiveness”, NBER Working Paper No. 23350, National Bureau of Economic Research. 
Bosio, Erica, Jean Arlet, Antoni Albert Nogues Comas, and Nicole Anouk Leger. 2018. "Road Costs Knowledge System (ROCKS) - Update,” The World Bank, Washington, DC.

Botero, Juan, Simeon Djankov, Rafael La Porta, Florencio Lopez-De-Silanes, and Andrei Shleifer. 2004. “The Regulation of Labor,” The Quarterly Journal of Economics, 119(4): 1339-1382.

Botero, Juan, Alejandro Ponce, and Andrei Shleifer. 2013. "Education, Complaints, and Accountability,” Journal of Law and Economics, 56(4): 959-996.

Burgess, Robin, Remi Jedwab, Edward Miguel, Ameet Morjaria, and Gerard Padró i Miquel. 2015. “The Value of Democracy: Evidence from Road Building in Kenya,” American Economic Review, 105(6): 1817-51.

Campos, Nicolas, Eduardo Engel, Ronald D. Fischer, and Alexander Galetovic. 2019. "Renegotiations and Corruption in Infrastructure: The Odebrecht Case," Available at http://dx.doi.org/10.2139/ssm.3447631.

Center for Systemic Peace. 2019. Polity IV Project, Political Regime Characteristics and Transitions, 1800-2018, Vienna, VA, USA.

Collier, Paul and Martina Kirchberger. 2016. "The Cost of Road Infrastructure in Low- and Middle-Income Countries,” World Bank Economic Review, 30(3): 522-548.

Colonnelli, Emanuele and Mounu Prem. 2020. "Corruption and Firms,” Available at SSRN: https://ssrn.com/abstract=2931602 or http://dx.doi.org/10.2139/ssrn.2931602.

Conley, Timothy and Francesco Decarolis. 2016. "Detecting Bidders Groups in Collusive Auctions," American Economic Journal: Microeconomics, 8(2): 1-38.

Coviello, Decio and Stefano Gagliarducci. 2014. "Publicity Requirements in Public Procurement: Evidence from a Regression Discontinuity Design,” Journal of Public Economics, 109: 76-100.

Coviello, Decio and Stefano Gagliarducci. 2017. "Tenure in Office and Public Procurement," American Economic Journal: Economic Policy, 9(3): 59-105.

Coviello, Decio, Andrea Guglielmo and Giancarlo Spagnolo. 2018. “The Effect of Discretion on Procurement Performance,” Management Science, 64(2):715-738. 
Decarolis, Francesco. 2014. "Awarding Price, Contract Performance, and Bids Screening: Evidence from Procurement Auctions,” American Economic Journal: Applied Economics, 6(1): 108-132.

Decarolis, Francesco and Giuliana Palumbo. 2015. "Renegotiation of Public Contracts: An Empirical Analysis,” Economics Letters, 132(C): 77-81.

Decarolis, Francesco, Leonardo M. Giuffrida, Elisabetta Iossa, Vincenzo Mollisi, and Giancarlo Spagnolo. 2019. "Bureaucratic Competence and Procurement Outcomes,” NBER Working Paper No. 24201, National Bureau of Economic Research.

Decarolis, Francesco, Giancarlo Spagnolo, and Riccardo Pacini. 2020a. "Past Performance and Procurement Outcomes,” NBER Working Paper No. 22814, National Bureau of Economic Research.

Decarolis, Francesco, Ray Fisman, Paolo Pinotti, and Silvia Vannutelli. 2020b. "Corruption in Procurement: New Facts from Italian Government Contracting”, mimeo.

Di Tella, Rafael and Ernesto Schargrodsky. 2003. "The Role of Wages and Auditing During a Crackdown on Corruption in the City of Buenos Aires,” Journal of Law and Economics, 46(1): 269-292.

Djankov, Simeon, Rafael La Porta, Florencio Lopez-De-Silanes, and Andrei Shleifer. 2002. "The Regulation of Entry,” The Quarterly Journal of Economics, 117(1): 1-37.

Djankov, Simeon, Edward Glaeser, Rafael La Porta, Florencio Lopez-de-Silanes, and Andrei Shleifer. 2003a. “The New Comparative Economics,” Journal of Comparative Economics, 31 (4): 595-619.

Djankov, Simeon, Rafael La Porta, Florencio Lopez-De-Silanes, and Andrei Shleifer. 2003b. “Courts,” The Quarterly Journal of Economics, 118(2): 453-517.

Djankov, Simeon, Oliver Hart, Caralee McLiesh, and Andrei Shleifer. 2008a. "Debt Enforcement around the World,” Journal of Political Economy, 116(6): 1105-1149.

Djankov, Simeon, Rafael La Porta, Florencio Lopez-de-Silanes, and Andrei Shleifer. 2008b. "The Law and Economics of Self-Dealing,” Journal of Financial Economics, 88(3): 430-465. 
Djankov, Simeon, Rafael La Porta, Florencio López-de-Silanes, and Andrei Shleifer. 2010. "Disclosure by Politicians," American Economic Journal: Applied Economics, American Economic Association, 2(2): 179-209.

Duflo, Esther, Rema Hanna, and Stephen P. Ryan. 2012. "Incentives Work: Getting Teachers to Come to School,” American Economic Review, 102(4): 1241-78.

Faccio, Mara. 2006. “Politically Connected Firms,” American Economic Review, 96(1): 369-386.

Fisman, Raymond. 2001. "Estimating the Value of Political Connections.” American Economic Review, 91(4): 1095-1102.

Freedom House. 2020. Freedom in the World 2020, Washington DC.

Flyvbjerg, Bent, Mette K. Skamris Holm, and Søren L. Buhl. 2003. "How Common and How Large are Cost Overruns in Transport Infrastructure Projects?” Transport Reviews, 23(1): 71-88.

Glaeser, Edward L., Giacomo AM Ponzetto, and Andrei Shleifer. 2007. "Why Does Democracy Need Education?” Journal of Economic Growth, 12(2): 77-99.

Hart, Oliver and John Moore. 1988. “Incomplete Contracts and Renegotiation,” Econometrica, 56(4): 755-785.

Hart, Oliver, Andrei Shleifer, and Robert W. Vishny. 1997. “The Proper Scope of Government: Theory and an Application to Prisons,” Quarterly Journal of Economics, 112(4): 1127-1161.

Kelman, Steven. 1990. "Procurement and public management: The Fear of Discretion and the Quality of Government Performance,” AEI Press, Washington, DC.

Kelman, Steven. 2002. “Remaking Federal Procurement,” Public Contract Law Journal, 31(4): 581-622.

La Porta, Rafael, Florencio Lopez-De-Silanes, and Andrei Shleifer. 1999. “The Quality of Government,” The Journal of Law, Economics, and Organization, 15(1): 222-279.

Lichand, Guilherme and Gustavo Fernades. 2019. “The Dark Side of the Contract: Do Government Audits Reduce Corruption in the Presence of Displacement by Vendors?” University of Zurich, Switzerland, mimeo. 
Milligan, Kevin, Enrico Moretti, and Philip Oreopoulus. 2004. "Does Education Improve Citizenship? Evidence from the United States and the United Kingdom,” Journal of Public Economics, 88: 1667-95.

Mironov, Maxim and Ekaterina Zhuravskaya. 2016. "Corruption in Procurement and the Political Cycle in Tunneling: Evidence from Financial Transactions Data,” American Economic Journal: Economic Policy, 8(2): 287-321.

Olken, Benjamin. 2007. "Monitoring corruption: Evidence from a field experiment in Indonesia,” Journal of Political Economy, 115(2): 200-249.

Olken, Benjamin, Abhijit Banerjee, Rema Hanna, Jordan Kyle, and Sudarno Sumarto. 2018. “Tangible Information and Citizen Empowerment: Identification Cards and Food Subsidy Programs in Indonesia,” Journal of Political Economy, 126(2): 451-491.

Pande, Rohini. 2011. "Can Informed Voters Enforce Better Governance? Experiments in LowIncome Democracies,” Annual Review of Economics, 3: 215-237.

Porter, Robert and John Zona. 1993. “Detection of Bid Rigging in Procurement Auctions,” Journal of Political Economy, 101(3): 518-38.

Rasul, Imran and Daniel Rogger. 2018. “Management of Bureaucrats and Public Service Delivery: Evidence from the Nigerian Civil Service,” The Economic Journal, 128(608): 413-446.

Sequeira, Sandra and Simeon Djankov. 2014. "Corruption and Firm Behavior: Evidence from African Ports,” Journal of International Economics, 94(2): 277-294.

Shleifer, Andrei and Robert Vishny. 1993. “Corruption,” Quarterly Journal of Economics, 108: 599-617.

Spagnolo, Giancarlo. 2012. “Reputation, Competition and Entry in Procurement,” International Journal of Industrial Organization, 30(3): 291-296.

Stigler, George. 1971. “The Theory of Economic Regulation,” Bell Journal of Economics and Management Science, 3: 3-18. 
Svensson, Jacob. 2003. "Who Must Pay Bribes and How Much? Evidence from A Cross Section of Firms,” The Quarterly Journal of Economics, 118(1): 207-230.

Szucs, Ferenc. 2017. “Discretion and corruption in public procurement," University of California at Berkeley, job market paper.

World Bank. 2020. World Development Indicators, Washington, DC.

World Economic Forum. 2019. Global Competitiveness Report 2019: How to End a Lost Decade of Productivity Growth, Geneva, Switzerland. 


\section{Appendix A: Description of variables}

For all questions discussed below, the term "legal framework" refers to the body of instruments (laws, acts, regulations, etc.) that regulate the entire procurement process (from needsassessment to post-tendering). This only includes legal instruments that are procurement-specific and mandatory. ${ }^{7}$

\section{Laws and Practices: Variable Construction and Examples}

On transparency, respondents are asked seven questions gauging whether the law mandates the publication of each of the following seven documents: procurement plans; model procurement documents and standard contract conditions; tender notices; tender documents and technical specifications; notices of award and bidding results; contracts; and contract amendments. All seven questions are Yes/No questions, asking respondents to indicate whether the law mandates the PE to publish each of these documents. To build the transparency index, each "Yes" answer is given a score of 1 , and each "No" answer a score of 0 . The transparency law index is the average of the scores for each of the 7 questions.

In Argentina, PE’s are not mandated by law to publish annual procurement plans (a score of 0), but all documents related to the procurement process stricto sensu - model documents, tender notices, tender documents, and awards - must be published (a score of 1 for each of these 4 documents). Neither the contract itself nor its subsequent modifications must be published by law (a score of 0 for each of these 2 sets of documents). Argentina scores 4 out of 7 points in the transparency law index, for an average of 0.57 .

Respondents are also asked seven mirroring practice questions, measuring whether the same documents are readily available to bidders in the majority of procurement processes. For example, the mirroring practice question asks: "In practice, do tender notices need to be made publicly available online by the procuring entity?” These seven questions are also Yes/No questions, and respondents are asked to supplement their answers with links to the materials. The

\footnotetext{
${ }^{7}$ Guidelines that are self-imposed by the procuring entity and for "recommended" use, are not included. Standard bidding documents and general contract terms are included whenever their use by the procuring entity is mandatory. Customizable contract terms are not considered, as they can be modified at will by the procuring entity. Laws that are not procurement-specific and only contain general obligations on fairness and transparency are not included.
} 
team verifies such links directly before coding a "Yes" answer. The transparency practice index is built by attributing a score of 1 to each "Yes" answer and 0 to each "No" answer. In Argentina, public procurement plans are not available in practice (a score of 0 ). Model documents and tender notices are publicly available (1 for each), while PE’s do not publish tender documents and awards despite a legal obligation to do so (0 for each). Contracts and contract amendments are not published either ( 0 for each). Argentina scores 2 out of 7 points in the transparency practice, for an average of 0.29 .

In more than a fourth of the sample - 52 countries - the procuring entity is not required by law to publish the award, so that the results of the auction are only made available to the winning bidder, and losing contractors are deprived of an opportunity to understand - and challenge - the reasons behind their loss. In several countries, documents are not published in practice despite a legal obligation to do so. The Argentine law mandates the publication of tender documents, but the relevant PE only makes them available upon payment of a fee. Conversely, in some countries the law does not mandate publication, but documents are nonetheless available. In the United Kingdom, the law requires PE's to prepare annual procurement plans, without mandating their publication. However, once they are prepared, and given the availability and spread of online tools, PE's just choose to put them on their website.

The competition law index asks 6 questions related to legal provisions favoring competition throughout the entire procurement process (and there are six parallel practice questions). The first question asks whether, according to the law, open tendering is the default method of procurement for a routine road resurfacing contract. Open tendering is defined as the process in which any interested firm may submit an economic offer in response to a call for competition. A "Yes" carries a score of 1 and "No" carries 0 . The mirror question in practice asks respondents to indicate whether the majority of road resurfacing contracts are in fact procured through open tendering. Respondents are presented with three different answer options: (i) open tendering is the default by law and also the most common in practice; (ii) open tendering is not the default by law, but remains the most common in practice; and (iii) other methods of procurement, such as restricted tendering, direct award, reverse auctions, competitive dialogue, etc., are the most common. Answer options (i) and (ii) are coded as "Yes", with a score of 1. Answer option (iii) is coded as "No", with a score of 0 . 
In many European countries - such as Austria and Italy - the law gives PE's the discretion to choose between open tendering and restricted tendering (a score of 0 on whether open tendering is the default by law), but open tendering is still most frequently used (a score of 1 on whether open tendering is the most common practice). Similarly, in France the use of open tendering is discretionary (a score of 0 on whether open tendering is the default by law), but the relevant PE introduced a guideline - not mandatory, but strictly followed - imposing the use of open tendering for all contracts above $€ 1,000,000$ (a score of 1 on whether open tendering is the most common in practice).

The second question asks whether, in an open tendering procedure, the PE can require bidders to participate in a prequalification process, which can limit competition. A "Yes" answer corresponds to a score of 0 , a "No" answer corresponds to a score of 1 . The mirroring practice question asks respondents to indicate how often prequalification is used for a road resurfacing contract. Experts are presented with 5 answer options. Prequalification happens: (i) very rarely (less than $10 \%$ of cases); (ii) rarely (10-25\% of cases); (iii) occasionally (25-50\% of cases); (iv) often (50-90\% of cases); and (v) very often (more than $90 \%$ of cases). If prequalification is used in less than $25 \%$ of cases (very rarely or rarely), the score of 1 ; it is 0 otherwise. Worldwide, in 103 out of 187 countries prequalification takes place in more than $25 \%$ of cases.

The third question asks whether the legal framework prohibits dividing contracts to circumvent thresholds for open tendering. The obligation for PE's to use open tendering is usually tied to a monetary threshold, but they may circumvent the threshold by splitting the contract and then using a non-open procedure that limits competition. A score of 1 is given if dividing contracts is forbidden by law, a score of 0 if it is not. The practice question asks how often contracts are divided to circumvent procurement rules. If this occurs in less than $25 \%$ of cases, the score is 1 , and 0 otherwise. This phenomenon is extremely widespread, with 73 countries scoring a "0" in practice. Local experts in Mali and Sudan explained that procuring entities frequently split works into several contracts to award them to contractors of their choice with little or no publicity.

The fourth question asks whether the law mandates a minimum time limit between the advertisement of the tender notice and the submission deadline for an open tendering procedure (a score of 1). In the absence of such a rule, a procuring entity can limit competition by setting demanding technical specifications and imposing a tight timeline. In Bulgaria, the Agency for 
Road Maintenance posted a $€ 100$ million procurement notice on December 29, 2016, to solicit bids for the construction of an electronic toll system, with the closing day for bids of January 4. Not surprisingly, only one firm met the deadline. The practice question asks how often the PE does not advertise procurement opportunities long enough so as to restrict competition. If rarely or very rarely, the score is 1 . If occasionally, often or very often, the score is 0 .

The fifth question in the competition law index asks whether the legal framework requires the PE to proceed to bid opening immediately after the deadline for bid submission has been reached. A score of 1 is attributed to a "Yes" answer, 0 to "No". The mirror practice question asks whether bids are immediately opened in practice; 1 if "Yes", 0 if "No".

The sixth question asks whether there is a standstill period between public notice of award and contract signing that suspends the procurement process to allow unsuccessful bidders to challenge the award decision. A score of 1 is attributed to a "Yes" answer, 0 to "No". The mirroring practice question asks whether the filing of a challenge against the award does in fact suspend the process (a score of 1 ).

In Lao PDR, half the elements measured by the competition law index are regulated. In particular, open tendering is the default method of procurement (a score of 1), the legal framework mandates a minimum time limit between the advertisement of the tender notice and the submission deadline (a score of 1), and the division of contracts is forbidden (a score of 1). Lao PDR thus scores 3 out of 6 and obtains a score of 0.5 on the competition law index. Practice, however, lags behind. Even though open tendering is the default by law, PE's prefer to use prequalification to pre-screen candidates (a score of 0 in both). In more than $90 \%$ of procurement processes, the procuring entity does not advertise procurement opportunities long enough (a score of 0) and bid opening is not carried out immediately (a score of 0 ). The division of contracts in practice is uncommon, and challenges usually suspend the award process (a score of 1 in each). With 2 out of 6 points, Lao PDR's score on the competition practice index is 0.33 .

The limits to exclusion questions, both by law and in practice, look at 5 issues. The first question asks whether the legal framework establishes the minimum content of the tender notice and tender documents. These are often regulated separately, but both must be regulated for the answer to be coded as "Yes". If no regulation exists, or only one of two aspects is regulated, the 
answer is coded as "No". Because narrowly defined tender specifications and tender documents make it easier to exclude bidders, a "No" answer carries a score of 1, and a "Yes" carries a score of 0. In Bangladesh and the Russian Federation technical specifications are often drafted so narrowly that only one company satisfies them. These can include a specific type of asphalt with no obvious quality advantage that only one company in the country produces, for example. Or it can include a requirement to have performed the exact same contract for the PE in the last 7 years, thus creating and intrinsic and recurrent bias toward a single contractor. The practice question asks how often the PE defines technical specifications to benefit a specific bidder. If in less than 25\% of cases, a score of 1 , otherwise 0 .

The second question asks whether the law requires the PE to make clarifications publicly available to everyone (including to companies that did not participate in the bidding process) to minimize one-on-one interactions with bidders. Respondents are presented with 4 answer options: the PE (i) addresses all clarifications in a public meeting; (ii) must answer and communicate the answer to all other bidders; (iii) must answer, but is not always required to communicate the answer to all other bidders; and (iv) only answers the relevant bidder. A score of 1 is given if the procuring entity must address all clarifications in a public meeting, making it more difficult to exclude bidders and minimizing one-on-one interactions, a score of 0 otherwise. The mirroring practice question asks how often the PE holds informal meetings with individual bidders. If in less than $25 \%$ of cases, a score of 1 , otherwise 0 .

The third question asks which award criterion is used for a routine road maintenance contract by law. Three answer options are available: (i) price; (ii) price and other elements, i.e. best value for money; or (iii) the choice is left at the discretion of the PE. Using price as the only award criterion makes it harder for the PE to exclude bidders, a score of 1 . All other options make it easier, a score of 0 . The mirroring practice question asks how often the PE changes the award criterion after the bids are opened. If in less than $25 \%$ of cases, a score of 1 , otherwise 0.

The fourth question examines whether the legal framework establishes what constitutes an abnormally low bid and the criteria to handle such a bid. Having such a criterion makes it more difficult for the PE to exclude bidders (a score of 1). The practice question asks how often private sector companies submit recklessly low bids to win the tender. A score of 1 is recorded if Rarely or Very Rarely, and 0 in all other cases. 
The fifth question asks whether the legal framework defines what constitutes a nonsubstantial error. Regulating non-substantial errors makes it more difficult for the PE to exclude a score of 1 . The practice question asks whether the bidder would be given the opportunity to rectify such errors before disqualification. If so, it is harder for the PE to exclude - a score of 1 . If not, it is easier, a score of 0 .

Last, the integrity of contract indexes by law and in practice look at 6 types of restrictions on the PE's discretion during the life of the contract. The first is whether, by law, the PE is required to have already allocated budget to a specific project before tendering. Respondents are presented with three answer options: (i) yes, there is a specific budget allocation; (ii) yes, a certificate is required; and (iii) no. If the law requires a specific budget allocation and/or a budget certificate, the answer is coded as "Yes", a score of 1 . If no such requirement exists in the law, the answer is "No", and the score is 0 . The practice question asks the percentage of cases in which the procuring entity awards a contract without having already set aside all the necessary funds. If this happens in less than $25 \%$ of cases (i.e. rarely or very rarely), a score of 1 is assigned, 0 otherwise. Data from Tunis revealed that without a specific budget allocation or a certificate securing funds for each tendered project, procuring entities find themselves with invoices they cannot pay. In fact, it is not unusual for the relevant PE to have to return part of its budget before the end of the fiscal year, leaving it exposed to payments it cannot make. Delays in payment create considerable slowdowns, as contractors stop working until they are paid.

The second element relates to subcontracting. Respondents are asked to indicate which of the following three dimensions of subcontracting is regulated by law: (i) “features”, i.e. the administrative process to subcontract, the limits of subcontracting, the authorizations required, etc.; (ii) "disclosure”, i.e. when and how companies should inform the PE of their intent to subcontract; and (iii) "liability", i.e. the responsibility of the contractor and subcontractor in case of poor performance. The answer is coded as "Yes" - a score of 1 - only when all three aspects are regulated. All other options are coded as "No" - a score of 0 . The practice question asks respondents to identify whether contractors frequently employs subcontractors that were neither properly selected nor disclosed during the tendering process (a score of 0 if this happens in more than $25 \%$ of contracts). 
The next two elements relate to contract execution. Respondents are asked to indicate how renegotiations and additional works are regulated. Renegotiations are defined as substantial changes to the original contract terms that lead to new contract clauses. Respondents are asked to indicate whether some key aspects of renegotiation - including process, limits and disclosure requirements - are regulated (a score of 1). The mirroring practice question gauges how often the renegotiation process is abused to increase the price or the scope of the project without another competitive process. If Rarely or Very Rarely, a score of 1 , otherwise 0.

Additional works are all complementary works not included in the initial contract or tender documents but are related to the initial works and thus awarded to the same contractor. These works usually become needed during the execution of the original contract and are awarded to the original contractor through non-competitive methods of procurement. The law question asks whether additional works can be procured through direct award (a score of 1 ) or whether complete discretion is left to the PE on the process to award such works (a score of 0 ). The mirroring practice question tests how often additional works are in fact awarded through non-competitive measures. If Rarely or Very Rarely, a score of 1 is assigned; otherwise 0 . In many countries, renegotiations and additional works are completely unregulated, but characterize more than $50 \%$ of contracts.

The fifth and sixth elements relate to payment and ask whether the legal framework establishes a time frame within which the procuring entity must process the payment once an invoice is received (a score of 1 if "Yes", 0 if "No") and whether the company is entitled to claim interest on late payments if the PE does not pay within the legally-established timeframe (a score of 1 if "Yes”, 0 if “No”). The practice questions ask how often payment is processed in the legallymandated timeline and how often interests on late payments are actually paid. If payments are made on time in more than 50\% of cases (“often” or "very often”), a score of 1 is recorded. If not, 0 . The same coding applies if interest on late payments is actually paid to companies in more than half of the procurement processes.

In Singapore, the law does not require the PE to have already allocated budget before tendering (a score of 0), but it usually does so in practice (a score of 1). Subcontracting, renegotiations, and additional works are completely unregulated (a score of 0 on each of these three questions in the integrity of contract law index). The subcontracting and renegotiation processes in practice are not abused by the procuring entity (a score of 1 in each) and direct award 
of additional works is unusual (a score of 1). The law does not contain a deadline for payment of invoices (a score of 0 ) but does mandate the payment of interest on late payments (a score of 1 ). In practice, payments are timely in more than $90 \%$ of cases (a score of 1 ), but interest is rarely paid (a score of 0 ). Singapore scores 1 out of 6 on the integrity of contract law index, or 0.17 . In practice, it scores 5 out of 6 , or 0.83 .

The Law and Practice indices are the sums of their four subindices.

\section{Outcomes}

The outcomes we measure are corruption, Process, and Product.

Respondents on the corruption question are presented with 5 answer options, to indicate whether bribing happens: (i) very rarely (less than $10 \%$ of cases); (ii) rarely (10-25\% of cases); (iii) occasionally (25-50\% of cases); (iv) often (50-90\% of cases); and (v) very often (more than $90 \%$ of cases). In Colombia, bidders resort to bribes in $50-90 \%$ of road procurement cases; in Myanmar bribes are reported in more than $90 \%$ of such cases. The variable is scored by taking the average of the answer category, for example Colombia scores 0.70 and Myanmar scores 0.95. High scores mean bad outcomes.

Several inputs go into the construction of the Product index. Questions on time benchmark the efficiency of the procurement process from the moment the procuring entity decides to advertise the procurement opportunity, until the contract is successfully executed and the last payment is made. Time is measured for two phases of the procurement life-cycle: the bidding phase, which covers all interactions between the advertisement of the procurement opportunity and the commencement of the works measured in the case study, and the contract management phase, which measures all interactions with government agencies that delay the execution of the contract. The measure captures the median duration in calendar days that our respondents indicate is necessary in practice to complete a procedure with minimum follow-up with government agencies and includes all typical delays that a construction company would experience when dealing with the procuring entity. Time equals $\log$ (Number of days).

The bidding process can take as few as 149 days in Taiwan or as many as 801 days in Guinea-Bissau, where just obtaining permits and a notice to commence the works takes 420 days. 
During the execution of the contract, inspections and payment are the largest sources of delay. Obtaining payment takes more than one year in Haiti and Iran, while companies are left waiting more than nine months for an inspection in Mongolia and Mozambique.

The question on overruns measures how often the project is delivered within the original budget. Respondents are presented with the same answer options as for other frequency questions, with a high score if works are delivered within the original budget. In 13 countries in the sample - including Malawi and Peru - the original budget estimate is met in less than 10 percent of procurement cases. In 52 countries - including Serbia and Tunisia - it is met in less than 25\% of road procurement contracts. Fiji, Lichtenstein and Singapore are the only three countries in the sample meeting the original budget in more than $90 \%$ of contracts. The variable is scored by taking the average of the answer category, then subtracting from one to be consistent with the other two variables in the Product index. This implies, for example, that Malawi gets a score of 0.95 (1-0.05), Serbia gets a score of $0.825(1-(0.25+0.10) / 2)$, while Singapore gets a score of 0.05 (1-0.95).

The question on the low quality of public works asks how often the contract is executed with less quality or with different technical specifications than those submitted during the tender process. In Cameroon and Malawi, more than $90 \%$ of road works projects are delivered with lower than expected quality. In 15 countries - including Australia and Japan - road works projects are delivered with the lower quality standards then agreed-upon in the original contract in less than $10 \%$ of cases. The variable is scored by taking the average of the answer category, for example Cameroon gets a score 0.95, while Australia scores 0.05.

The index of Product is the z-score of these three variables. Singapore scores highest, at 6.45, followed by Korea (5.22) and Australia (4.82). At the opposite end, Venezuela scores lowest, at -6.12, followed by Haiti (-5.05) and Timor Leste (-4.98).

Several questions go into the measure of the Efficiency of Process as well. For each of these questions, respondents are presented with 5 answer options: (i) very rarely (less than $10 \%$ of cases); (ii) rarely (10-25\% of cases); (iii) occasionally (25-50\% of cases); (iv) often (50-90\% of cases); and (v) very often (more than $90 \%$ of cases). Efficiency of Process is scored by taking the average of the answer category. High scores signify bad outcomes. 
The favoritism variable measures how often procuring entities circumvent public procurement rules by interpreting selection criteria in a way that favors a specific bidder. In 70 countries - including Canada and Denmark - this happens in less than 25\% of cases. In Ecuador and Mexico, favoritism characterizes more than $90 \%$ of procurement projects.

The question on collusion asks whether procuring entities and private sector companies prevent market entry to other competitors. Collusion is prominent in eastern Europe. In several countries in the region - including Azerbaijan, Tajikistan and Uzbekistan - collusion plagues more than $50 \%$ of all road procurement contracts.

The absence of competition in procurement is assessed by how often non-competitive procurement methods are used instead of open tendering. In a quarter of countries in the sample 44 out of 187 - non-competitive procurement methods instead of open tendering are used in more than $50 \%$ of contracts, with peaks of more than $90 \%$ of contracts in Lao PDR. In Israel and New Zealand, only $10 \%$ of contracts use methods other than open tendering.

Process is the z-score of the three variables. Denmark, Germany, Hong Kong, Japan, Switzerland and another 16 countries score highest, at 3.68, followed by France, Morocco and the Netherlands (3.15). At the opposite end, Lao PDR and Niger score lowest, at -7.50 , followed by Myanmar and the West Bank and Gaza (-5.46).

Two other sources are used as outcomes. The World Economic Forum's executive opinion survey asks a question pertaining to the quality of road infrastructure. Executives are asked: "In your country, how is the quality (extensiveness and condition) of road infrastructure [1 = extremely poor-among the worst in the world; 7 = extremely good-among the best in the world] ?". We also measure the average quality of roads using Google data on the average driving speed from the first to the second largest business city, and from the second to the third one.

\section{Control Variables}

Five control variables feature in the analysis. The World Bank's Human Capital Index measures the amount of human capital that a child born today can expect to attain by age 18, given the risks of poor health and poor education that prevail in the country where she lives (Angrist et al 2019). Government effectiveness from the World Bank's World Development Indicators (World Bank 
2020), and is based on unobserved components model utilizing 33 data sources that are rescaled and combined to create an aggregate indicator. The measure captures perceptions of the quality of public services, the quality of the civil service and the degree of its independence from political pressures, the quality of policy formulation and implementation, and the credibility of the government's commitment to such policies. Freedom House's Functioning Government contains three components: Do the freely elected head of government and national legislative representatives determine the policies of the government; Are safeguards against official corruption strong and effective; and Does the government operate with openness and transparency (Freedom House 2020). The World Economic Forum's Efficiency of Legal Framework. The measure is constructed in response to the survey question: "In your country, how easy is it for private businesses to challenge government actions and/or regulations through the legal system?” The final measure is the Center for Systemic Peace (2019)'s Polity2, which captures political regime authority on a 21-point scale ranging from -10 (hereditary monarchy) to +10 (consolidated democracy). 


\section{Appendix B: Proofs of Proposition and Lemma}

Proof of Proposition 1: In a simple second price auction with known costs and no exclusion, both bidders bid their costs. If $K_{0}<K_{I}$ then the Outsider also receives the contract under the second price auction. In that case, consumer surplus is $Q_{O}-K_{I}$, and the PE's welfare is $\alpha\left(Q_{O}-K_{I}\right)$ as there is no scope for bribes. If $K_{0}>K_{I}$, then the Insider wins the auction, consumer surplus is $Q_{I}-K_{O}$, and the PE's welfare is $\alpha\left(Q_{I}-K_{O}\right)$.

In the excludable auction case, we begin with the default action of the PE if no bribe is paid.

If $K_{0}<K_{I}$, then the exclusion of the Outsider is the default if and only if $Q_{I}-Q_{O}>C_{\max }-K_{I}$.

If $K_{0}<K_{I}$, and $\Delta<-\left(C_{\max }-K_{I}\right)$, then the Insider pays no bribes because he knows that the Outsider will be excluded if a bargain is not reached. Exclusion is socially optimal and occurs without any bribes.

If $K_{0}<K_{I}$ and $-\Delta<C_{\max }-K_{I}$, then a corrupt bargain to exclude the Outsider selects the bribe to maximize $\left(\alpha\left(Q_{I}-C_{\max }\right)+B-\alpha\left(Q_{O}-K_{1}\right)\right)^{\beta}\left(C_{\max }-\theta B-K_{I}\right)^{1-\beta}$, subject to the constraint that $\frac{C_{\max }-K_{I}}{\theta} \geq \mathrm{B} \geq \alpha\left(C_{\max }-K_{I}+Q_{O}-Q_{I}\right)$, which requires that $\left(\frac{1}{\alpha \theta}-1\right)\left(C_{\max }-K_{I}\right)>\Delta$. In that case, the bribe is $\left(\frac{\beta}{\theta}+(1-\beta) \alpha\right)\left(C_{\max }-K_{I}\right)+(1-\beta) \alpha \Delta$ and consumer surplus is $Q_{I}-$ $C_{\max }<Q_{O}-K_{I}$. If $\left(\frac{1}{\alpha \theta}-1\right)\left(C_{\max }-K_{I}\right)<\Delta$, then both entities remain in the auction and consumer surplus is unchanged with discretion.

If $K_{0}>K_{I}$, then the procuring entity will exclude the insider if and only if $\Delta>C_{\max }-K_{O}$.

If $K_{0}>K_{I}$, then there are two corrupt possibilities: (1) the Insider and Outsider both remain in the auction even though the socially optimal outcome is to exclude the Insider, and (2) the Insider remains but the Outsider is excluded.

If $K_{0}>K_{I}$ and $\Delta<C_{\max }-K_{O}$, then the Insider wins the auction with or without bribery. Consequently, a corrupt bargain to exclude the Outsider selects the bribe that maximizes $\left(\alpha\left(Q_{I}-C_{\max }\right)+B-\alpha\left(Q_{I}-K_{O}\right)\right)^{\beta}\left(C_{\max }-\theta B-K_{O}\right)^{1-\beta}$, subject to the constraints that $\frac{C_{\max }-K_{O}}{\theta} \geq \mathrm{B} \geq \alpha\left(C_{\max }-K_{O}\right)$, or $1 \geq \theta \alpha$. In this case, the bribe equals $\left(\frac{\beta}{\theta}+(1-\beta) \alpha\right)\left(C_{\text {max }}-\right.$ $\left.K_{I}\right)=B$.

If $K_{0}>K_{I}$ and $\Delta>C_{\max }-K_{O}$, then the Insider is excluded from the auction if there are no bribes. Bribery can either leave both bidders in the auction, or exclude the Outsider.

If the Outsider is excluded, then the bargain maximizes $\left(\alpha\left(Q_{I}-C_{\max }\right)+B-\alpha\left(Q_{o}-\right.\right.$ $\left.\left.C_{\text {Max }}\right)\right)^{\beta}\left(C_{\max }-\theta B-K_{I}\right)^{1-\beta}$, subject to the constraint that $\frac{C_{\max }-K_{I}}{\theta} \geq \mathrm{B} \geq \alpha \Delta$. The bribe level 
satisfies $\quad B=(1-\beta) \alpha\left(Q_{O}-Q_{I}\right)+\frac{\beta}{\theta}\left(C_{\max }-K_{I}\right)$, so that joint welfare is $\beta^{\beta}(1-$ $\beta)^{1-\beta}\left(\alpha\left(Q_{I}-Q_{O}\right)+\frac{1}{\theta}\left(C_{\max }-K_{I}\right)\right)$.

If the Outsider is included then the bargain maximizes $\left(\alpha\left(Q_{I}-K_{O}\right)+B-\alpha\left(Q_{O}-\right.\right.$ $\left.\left.C_{\text {Max }}\right)\right)^{\beta}\left(K_{O}-\theta B-K_{I}\right)^{1-\beta}$, subject to the constraint that $\frac{K_{O}-K_{I}}{\theta} \geq \mathrm{B} \geq \alpha\left(Q_{O}-Q_{I}+K_{O}-\right.$ $C_{\text {Max }}$ ), which requires $\frac{K_{O}-K_{I}}{\alpha \theta}+C_{\max }-K_{0} \geq Q_{O}-Q_{I}$. The bribe satisfies $B=(1-$ $\beta) \alpha\left(Q_{O}-Q_{I}+K_{O}-C_{\text {Max }}\right)+\frac{\beta}{\theta}\left(K_{O}-K_{I}\right)$, so that joint welfare is $\beta^{\beta}(1-\beta)^{1-\beta}\left(\alpha\left(Q_{I}-Q_{O}+\right.\right.$ $\left.\left.C_{\text {Max }}-K_{O}\right)+\frac{1}{\theta}\left(K_{O}-K_{I}\right)\right)$. Joint welfare is higher in the corrupt bargain if the Outsider is excluded if and only if $1>\alpha \theta$.

Putting these conditions together, if $1>\alpha \theta$, then a corrupt bargain to exclude the Outsider and keep the Insider occurs if and only if $\frac{C_{\max }-K_{I}}{\alpha \theta} \geq \Delta$. In that case, social losses relative to the simple second price auction equal $C_{\max }-K_{O}$. If $\frac{C_{\max }-K_{I}}{\alpha \theta}<\Delta$, then the outsider is kept and the Insider is, excluded and there are social gains from discretion.

If $1<\alpha \theta$, then a corrupt bargain to keep the insider occurs if and only if $C_{\max }-K_{0}+\frac{K_{O}-K_{I}}{\alpha \theta} \geq$ $\Delta$, but in this case it bargain just replicates the simple second price auction, so there are no social welfare losses. If $1<\alpha \theta$ and $C_{\max }-K_{0}+\frac{K_{O}-K_{I}}{\alpha \theta}<\Delta$, the insider is excluded and there are social gains of $Q_{O}-Q_{I}+K_{0}-C_{\max }$ relative to the simple second price auction. If $1<\alpha \theta$ then $C_{\max }-$ $K_{0}+\frac{K_{O}-K_{I}}{\alpha \theta}>\frac{C_{\max }-K_{I}}{\alpha \theta}$ and if $1>\alpha \theta$ then $C_{\max }-K_{0}+\frac{K_{O}-K_{I}}{\alpha \theta}<\frac{C_{\max }-K_{I}}{\alpha \theta}$, so discretion is beneficial if and only if $\Delta>\operatorname{Max}\left[C_{\max }-K_{O}+\frac{K_{O}-K_{I}}{\alpha \theta}, \frac{C_{\max }-K_{I}}{\alpha \theta}\right]$. If $1>\alpha \theta$ and $\frac{C_{\max }-K_{I}}{\alpha \theta} \geq \Delta$, then discretion reduces consumer welfare. If $1<\alpha \theta$ and $C_{\text {max }}-K_{O}+\frac{K_{O}-K_{I}}{\alpha \theta} \geq \Delta$, then discretion does not impact consumer welfare.

Proof of Proposition 2: If the Insider has made a cost cutting investment, he is a low cost/low quality provider. In a regulated second price auction without exclusion, the Insider always reduces quality to win the bid. Consumer welfare is equal $Q_{O}-\Delta-K_{O}$.

As $K_{0}>K_{I}$ and $\Delta>C_{\max }-K_{O}$, then the Insider is excluded from the auction if there are no bribes. Bribes can either leave both bidders in the auction, or exclude the Outsider.

Following the logic of the Proof of Proposition 1, if $1>\alpha \theta$, then a corrupt bargain to exclude the Outsider occurs if and only if $\frac{C_{\max }-K_{I}}{\alpha \theta} \geq \Delta$. If $1<\alpha \theta$ and $C_{\max }-K_{0}+\frac{A}{\alpha \theta}>\Delta$, then there is a corrupt bargain with the Insider, but as we assume that $\Delta>C_{\max }-K_{O}+A$, there is never a corrupt bargain when $1<\alpha \theta$ and so the Insider earns zero profits if he has cut quality. 
If $\frac{C_{\max }-K_{O}+A}{\Delta}<\alpha \theta<1$, then the Insider is included and so earns zero profits. If $\frac{C_{\max }-K_{O}+A}{\Delta}>$ $\alpha \theta$, then the Outsider is excluded, the insider wins the auction, pays a bribe of $(1-\beta) \alpha \Delta+$ $\frac{\beta}{\theta}\left(C_{\max }-K_{O}+A\right)$ and so earns total profits of $(1-\beta)\left(C_{\max }-K_{O}+A-\alpha \theta \Delta\right)$.

If the insider does not cut costs, his quality is the same as the outsider's and $K_{0}<K_{I}$, so the default is not to exclude anyone and for the Insider to earn zero profits. If $\alpha \theta>1$, the Outsider is not excluded and the Insider loses the auction. If $\alpha \theta<1$, the Outsider is excluded and the Insider wins and earns profits after bribes of $(1-\beta)(1-\alpha \theta)\left(C_{\max }-K_{O}-A\right)$.

If $\alpha \theta>1$, the insider earns zero profits whether or not he cuts costs. By assumption he does not make the investment, and so is not excluded from the auction. The auction therefore yields consumer welfare of $Q_{O}-K_{O}-A>Q_{O}-\Delta-K_{O}$.

If $\frac{C_{\max }-K_{O}+A}{\Delta}<\alpha \theta<1$, Insider earns zero profits if he cuts costs, but positive profits if he does not. In this range, he does not invest and consumer welfare is $Q_{O}-C_{\operatorname{Max}}>Q_{O}-\Delta-K_{O}$.

If $\frac{C_{\max }-K_{O}+A}{\Delta}<\alpha \theta$, he earns profits after bribes of $(1-\beta)\left[\left(C_{\max }-K_{O}-a\right)-\left(C_{\max }-K_{O}-\right.\right.$ a) $\alpha \theta]$ if he does not cut costs, and $(1-\beta)\left[\left(C_{\max }-K_{O}+A\right)-\Delta \alpha \theta\right]$ if he does.

Discretion then leads to quality cuts if and only if $\alpha \theta<\frac{a+A}{\Delta-C_{\max }+K_{O}+a}<\frac{C_{\max }-K_{O}+A}{\Delta}<0$. In that case, consumer welfare is $Q_{O}-\Delta-C_{\text {Max }}$, which offers the worst case scenario of maximum price and minimum quality.

Proof of Proposition 3: If there is no bribe, the PE sets $\pi=1$, since added competition reduces costs and raise social welfare. In that case, the Insider receives zero profits. If the Outsider does not receive the signal then the Insider's profits equal $C_{\max }-K_{I}$.

If there is no law, a corrupt bargain to reduce transparency selects the bribe to maximize $\left(\alpha\left(1-\pi_{L}\right)\left(K_{1}-C_{\max }\right)+B\right)^{\beta}\left(\left(1-\pi_{L}\right)\left(C_{\max }-K_{1}\right)-\theta B\right)^{1-\beta}$, subject to the constraint that $\left.\frac{(1-\pi)\left(C_{\max }-K_{I}\right)}{\theta} \geq \mathrm{B} \geq \alpha\left(1-\pi_{L}\right)\right)\left(C_{\max }-K_{I}\right)$, or $\left(C_{\max }-K_{I}\right)\left(\frac{1}{\alpha \theta}-1\right) \geq 0$. Hence if $\alpha \theta>1$, the $\mathrm{PE}$ sets set $\pi=1$. If $\alpha \theta<1$, the $\mathrm{PE}$ sets $\pi=\pi_{L}$, and the bribe is $B=$ $\left(\frac{\beta}{\theta}+(1-\beta) \alpha\right)\left(1-\pi_{L}\right)\left(C_{\max }-K_{1}\right)$.

If there is a law, a corrupt bargain to reduce transparency selects the bribe to maximize $\left(\alpha\left(1-\pi_{L}\right)\left(K_{1}-C_{\max }\right)+B-\alpha z\right)^{\beta}\left(\left(1-\pi_{L}\right)\left(C_{\max }-K_{1}\right)-\theta B\right)^{1-\beta}$, subject to the constraint that $\left.\frac{(1-\pi)\left(C_{\max }-K_{I}\right)}{\theta} \geq \mathrm{B} \geq \alpha\left(1-\pi_{L}\right)\right)\left(C_{\max }-K_{I}\right)+\alpha z$, or $\left(C_{\max }-K_{I}\right)\left(\frac{1}{\alpha \theta}-1\right) \geq z$. Hence if $\alpha \theta>\frac{C_{\max }-K_{I}}{C_{\max }-K_{I}+z}$, the PE sets $\pi=1$. If $\alpha \theta<\frac{C_{\max }-K_{I}}{C_{\max }-K_{I}+z}$, then the PE sets $\pi=\pi_{L}$, and the bribe is $B=\left(\frac{\beta}{\theta}+(1-\beta) \alpha\right)\left(1-\pi_{L}\right)\left(C_{\max }-K_{1}\right)+(1-\beta) \alpha z$. 